\title{
Developments in Qualitative Mindfulness Practice Research: a Pilot Scoping Review
}

\author{
Pascal Frank $^{1}\left[\right.$ D $\cdot$ Marieke Marken ${ }^{2}$
}

Accepted: 3 September 2021 / Published online: 29 September 2021

(c) The Author(s) 2021

\begin{abstract}
Objectives While scholars are increasingly emphasizing the potential of qualitative mindfulness practice research (QMPR) for advancing the understanding of mindfulness practice, there has been no significant empirical inquiry looking at actual trends and practices of QMPR. Consequently, it has been impossible to direct research practices toward under-researched areas and make methodical suggestions on how to approach them. The aim of the present study was to analyze current trends and practices in QMPR in order to address these areas of need.

Methods Based on a scoping review, 229 qualitative studies published between 2000 and 2019 were analyzed in regard to their disciplinary backgrounds, research questions and intentions, type of mindfulness practice, target population, as well as practices of data collection and analysis.

Results A strong focus of QMPR lies in the inquiry of mindfulness-based interventions, particularly mindfulness-based stress reduction, mindfulness-based cognitive therapy, and adaptations. Over $10 \%$ of the publications do not fully specify the mindfulness practice. The efficacy and subjective experience of mindfulness practices constitute the dominant research interests of QMPR. Data collection is highly concentrated on practice participants and first-person data. Interpretative paradigms are the predominant analytical approach within QMPR. QMPR studies have a strong proclivity toward emphasizing the positive effects of mindfulness practice. Nine percent of all articles considered for our study did not fully disclose their analytical procedure. Adversarial research groups and pluralistic qualitative research remain scarce.

Conclusions Future QMPR should (i) include second- and third-person data, (ii) include dropouts and former mindfulness practitioners, (iii) fully disclose details on the mindfulness practice and data analysis, (iv) intensify the application of critical and deconstructivist paradigms, as well as pluralistic qualitative research, and (v) build adversarial research teams.
\end{abstract}

Keywords Mindfulness practice $\cdot$ Mindfulness meditation $\cdot$ Qualitative $\cdot$ Scoping review

Mindfulness has received rapidly increasing popularity throughout the last 20 years and shows no signs of peaking. While occasionally being the subject of scholarly publications before 2000 , ever since, annually publications have increased exponentially, raising by an average of $23.5 \%$ per year during the last decade to over 2800 articles in 2020 (Baminiwatta \& Solangaarachchi, 2021). Special attention is given to mindfulness practices, comprising both ancient

Pascal Frank

pascal.frank@leuphana.de

1 Institute for Environmental and Sustainability Communication, Leuphana University of Lüneburg, Universitätsallee 1, 21337 Lüneburg, Germany

2 Faculty of Life Sciences, Humboldt University Berlin, Unter den Linden 6, 10099 Berlin, Germany
Buddhist mindfulness meditations (MMs) (e.g., Vipassana, Zen meditation) and modern, secularized mindfulness-based interventions (MBIs) (e.g., mindfulness-based stress reduction [MBSR], mindfulness-based cognitive therapy [MBCT]) (Chiesa \& Malinowski, 2011; Hanley et al., 2016). Especially, the latter have received significant scholarly interest across various disciplines as a training to foster a plethora of seemingly desirable outcomes. These range from cognitive-emotional abilities (e.g., Chiesa et al., 2011) to attitudinal and value-related changes (e.g., Luberto et al., 2018) up to behavioral and performance-related effects (Barrett et al., 2016; Beauchemin et al., 2008). Supported by dozens of systematic literature reviews and meta-analyses mostly confirming its positive effects, mindfulness trainings have nowadays been introduced in a variety of areas of practice. These include, but are not limited to, health care and 
psychotherapy (Ivtzan, 2019), education (Schonert-Reichl \& Roeser, 2016), business and administration (Reb \& Atkins, 2015), sport and music performance (Baltzell, 2016), the military (Jha et al., 2015), or sustainability promotion (Barrett et al., 2016; Stanszus et al., 2017).

In view of this attention, it is not surprising that the mindfulness "hype" (van Dam et al., 2018) is increasingly approached with criticism. While the majority of critiques are related to the various applications of mindfulness trainings in the aforementioned areas of practice (e.g. Arthington, 2016; Furedi, 2014; Hyland, 2017; Reveley, 2016; Walsh, 2016), three major concerns have also been raised in regard to research on mindfulness, especially research on mindfulness trainings, namely (1) skepticism toward self-reported measures, (2) an insufficient description of the mindfulness practice under investigation, and (3) narrow research interests in (positive) effects of mindfulness practices.

First and foremost, the application of quantitative approaches using self-report-based mindfulness scalesapplied in the vast majority of mindfulness research-has come under attack (Davidson \& Kaszniak, 2015; Goldberg et al., 2019; Goyal et al., 2014; Grossman, 2008, 2019; Hanley et al., 2016; Quaglia et al., 2016; Van Dam et al., 2018). It is argued that the existing instruments (overviews can be found in Bergomi et al., 2013; Quaglia et al., 2016; van Dam et al., 2018) are rooted in semantic ambiguities surrounding the concept of mindfulness and often represent oversimplifications of its complex and multifarious nature. They tend to reduce mindfulness to specific qualities that may be associated with it, but which may also be attributed to other states and/or traits and do not capture the phenomenon, such as the ability to maintain attention or to be emotionally nonreactive. Furthermore, "self-reports on mindfulness questionnaires may reflect very different processes at different levels of training" (Davidson \& Kraszniak, 2015, p, 583). In this regard, experienced practitioners might perceive their mindfulness very differently than individuals with no or little mindfulness practice, who might not have developed the mental processes for internal attention that are required to appropriately answer mindfulness questionnaires.

The second problem identified in current research on mindfulness training is that the specific practices under investigation are not always described in sufficient detail. There is now a vast diversity of practices subsumed under the term "mindfulness practice" (see already Chiesa \& Malinowski, 2011), even though they can differ strongly in terms of object and length of actual meditation sessions, instructions, and the overall program in which they are embedded (Davidson \& Kaszniak, 2015; Dorjee, 2010; Hanley et al., 2016; van Dam et al., 2018). This diversity, notwithstanding current mindfulness practice research, does not always specify the applied practice, resulting in a mingling of findings rooted in highly heterogeneous activities.
The third issue concerns the focus of interest guiding mindfulness research (Davidson \& Kaszniak, 2015; Grossman, 2019; Hanley et al., 2016; van Dam et al., 2018). The majority on the effectiveness of mindfulness practices in regard to specific goals, such as health-related or performanceoriented outcomes. The inquiry of potential harm, adverse effects, or limitations of mindfulness practice, in contrast, has been neglected, and so has the identification of other factors potentially influencing the experience and effectiveness of mindfulness practice (e.g., the role of the teacher, group constellations, or theories and attitudes toward mindfulness). What is more, related studies have predominantly used self-reports as indicators for the effectiveness of mindfulness practices, hence omitting to include other persons' perspectives (e.g., instructors, friends, or family members) as potential sources of information for understanding mindfulness practice effects.

To address these problems, several suggestions have been made on how to improve the quality of research on mindfulness practice throughout the last decade. Among others, these include (a) a more nuanced investigation of the multifarious facets regarding the various subjective experiences of mindfulness practice and the various mechanisms potentially explaining its effects (Grossman, 2008; Krägeloh et al., 2019; van Dam et al., 2018), (b) a clear distinction between and indication of the mindfulness practice under investigation, including information on instructors (Davidson \& Kaszniak, 2015; Dorjee, 2010; Hanley et al., 2016; van Dam et al., 2018), (c) a systematic inquiry into the role of context and expectations of practitioners, as well as potential harm, adverse effects, and limitations of the practice (Davidson \& Kaszniak, 2015; Hanley et al., 2016; van Dam et al., 2018), and (d) broadening the methodical approaches used for the inquiry of mindfulness practice. Alongside recommendations, to conduct multimodal and mixed methods research (Krägeloh et al., 2019; van Dam et al., 2018) includes first-, second-, and third-person perspectives as sources of data (Davidson \& Kaszniak, 2015; Goldberg et al., 2019; van Dam et al., 2018) and involves adversarial collaboration (van Dam et al., 2018); scholars have especially suggested to intensify qualitative research approaches when investigating mindfulness practice (Garland \& Gaylord, 2009; Goyal et al., 2014; Grossman, 2008; Krägeloh et al., 2019; Quaglia et al., 2016).

Indeed, qualitative mindfulness practice research (QMPR) has contributed to advancing the understanding of mindfulness practice in various ways. For example, QMPR has complemented the standardized, quantitative mindfulness measures with insights into the subjective experience of engaging in these practices (compare Malpass et al., 2012). Such insights also carry the potential to discover novel effects in new domains of application (e.g., tennis performance, Cote et al., 2019; sustainable consumption behavior, 
Frank et al., 2019) and to reveal mechanisms potentially explaining effects indicated by quantitative measures (e.g. Hugh-Jones et al., 2018; Kerr et al., 2011). In particular, this kind of research allowed for a better understanding of how specific populations perceived mindfulness practices before and experienced these practices during participation (Banerjee et al., 2017; Martinez et al., 2015), as well as the experiences associated with specific types of practice (Jiga et al., 2019; Stanszus et al., 2019), allowing for a better adaptation of mindfulness-based interventions to target populations. Furthermore, qualitative research helped to understand how factors accompanying the delivery of mindfulness practice could influence the actual practice experience, such as group settings or the relation with the mindfulness teacher (Cormack et al., 2018; Larkin et al., 2012). Finally, recent qualitative research on mindfulness has shed light on potential harm and adverse effects associated with the practice (Baer, 2019; Lindahl et al., 2017).

Qualitative research methods carry unique potentials regarding the inquiry of mindfulness practice. Interpretiveconstructionist methods, such as qualitative content analyses, (auto-)ethnography, or phenomenology, can allow for a more open exploration of (potentially different) subjective experiences of the various mindfulness practices, the way people make sense of these, as well as possible effects experienced by practitioners (Garland \& Gaylord, 2009; Krägeloh et al., 2019). These methods could therewith help researchers to identify subtle, overlooked aspects and detect "mechanisms of change of mindfulness interventions" (Quaglia et al., 2016, p. 165). Critical approaches, potentially including mindfulness research based on grounded theory, can contribute to identifying contextual factors, adverse effects, and barriers to practicing mindfulness (Frank et al., 2019; Krägeloh et al., 2019). Deconstructive methods, such as discourse analysis or conversation analysis, can be used to investigate "prevailing social perceptions and interpretation patterns in participants' discourse around mindfulness, and whether these patterns" (Frank et al., 2019, p. 2457) affect the training experience. All of the aforementioned approaches can be combined in pluralistic qualitative research (Frank et al., 2019; Frost, 2011) or mixed method studies, demonstrating their suitability for multimodal inquiry on mindfulness practice. Furthermore, qualitative data collection is usually not limited to one source of data, meaning that it can take first-, second-, and third-person perspectives into account. Finally, interpretation groups constitute an established practice in qualitative research, allowing for a systematic integration of multi-perspectivity and hence adversarial collaboration (Reichertz, 2013).

In light of this potential, it is somewhat surprising that systematic descriptions and analyses of QMPR are, to our knowledge and research, nonexistent. So far, published meta-ethnographies and literature reviews have focused on specific MBIs or look at particular applications of mindfulness (e.g., Dussault et al., 2020; Malpass et al., 2012). While scholars continue to emphasize QMPR's value for advancing the understanding of mindfulness practice, there has been no empirical inquiry looking at actual trends and practices of qualitative research in the field. It hence remains unclear whether current QMPR responds to the broader problems of mindfulness research and follows the suggestions to overcome the latter. As a consequence, it is also difficult to direct qualitative research practices toward under-researched areas or make methodical and methodological suggestions as to how to approach such areas.

The aim of the present study is to pilot an analysis of current trends and practices in qualitative mindfulness practice research. Based on a scoping review, it looks at 229 QMPR articles published between 2000 and 2019 and analyzes them with regards toing their disciplinary backgrounds, research interests, type of mindfulness practice, target population, as well as data collection and analyses approaches. Therefore, this work seeks to provide a basis of information on QMPR, so that future research can recognize what has been done so far, what is missing, and what could be improved in the face of the general shortcomings of current mindfulness research and the aforementioned suggestions to address the latter.

\section{Method}

In order to get an overview of the existing qualitative studies in the field of mindfulness and its development over the years, we conducted a scoping review (Arksey \& Malley, 2005). Among other reasons, scoping reviews have been specifically developed to examine how research is conducted on a certain topic or field (Munn et al., 2018). Due to the method's focus on screening a broad scope of studies in the field and obtaining an overview of their key characteristics, it appeared to be the most appropriate method for answering our research questions. In conducting our research, we followed the rules and suggestions proposed by Paul and Criado (2020) on writing impactful literature reviews.

\section{Procedure}

For our literature review, we utilized the databases SCOPUS and Web of Science (WoS). SCOPUS is the biggest abstract and citation database of peer-reviewed scientific articles, and many literature reviews rely on this database (Paul \& Criado, 2020). WoS is also among the most well-known bibliographic databases and was consulted to complement the SCOPUS search. While SCOPUS and WoS might not cover all QMPR publications, we presumed that these databases would provide a general overview of the field and would hence be suitable for our interests. Further steps to augment 
the quantity of relevant publications such as "bread crumbing" or "pearl growing" methods were left out, as it was not the aim of the study to capture all articles. Furthermore, we did not apply common search frameworks (e.g., PICO or SPICE), as our review was intentionally not limited to any specific population, outcomes, or evaluations that must be indicated in these frameworks. We limited our review to articles published in English.

Two preliminary reflections were made to specify the study selection for the scoping review. Firstly, we decided to limit our review to studies referring to mindfulness as a practice, since the focus of our inquiry lay on QMPR. Therefore, we excluded studies examining mindfulness as a state (Lau et al., 2006) or trait (Baer et al., 2006). Secondly, we were interested in those qualitative studies investigating mindfulness trainings based on mindfulness meditation practice. We excluded some MBIs (e.g., acceptance and commitment therapy $[\mathrm{ACT}]$, dialectical behavioral therapy [DBT]) that do not necessarily incorporate meditation practice (Chiesa $\&$ Malinowski, 2011), so that we wanted to exclude them from the study.

Due to the aim of providing an overview of QMPR, the search string was set to be relatively broad. However, some specifications about the practices examined were made in order to include the most common MBIs as well as MMs. Given that MBSR and MBCT are mindfulness interventions that include mindfulness meditation and have received the most scholarly attention (Chiesa \& Malinowski, 2011), and that Vipassana and Zen are the two most popular forms of traditional mindfulness meditation practices in mindfulness research (ibid.), we included these terms in the search string alongside MM. These deliberations led to the following search string:

(TITLE-ABS-KEY (mindfulness AND qualitative)) AND ( mbsr OR mbct OR mm OR vipassana OR zen) AND ( LIMIT-TO ( DOCTYPE, “ar”) OR LIMIT-TO (DOCTYPE, “ip”)) AND (LIMIT-TO (LANGUAGE, “English”)).
Boolean operator "AND" and "OR" were used in order to specify the search. The operator "AND" ensured that the found articles included both the criteria "mindfulness" and "qualitative," whereas the operator "OR" implied that at least one of the named practices in the search string (MBSR, MBCT, MM, Vipassana, Zen) should be found in the article.

The data collection consisted of two steps: a data base research and a screening process. In the first step, we collected the studies that fulfilled our search string criteria. In the second step, a coding scheme was used to identify the relevant studies for the scoping review and exclude those that did not correspond to our inclusion criteria. In order to be considered in our review, the article needed to (a) be written in English, (b) be a peer-reviewed published article or article in press, (c) reflect empirical work on mindfulness meditation practice, and (d) apply qualitative research methods.

Following these criteria, we excluded all articles describing meta-analyses of other studies, literature reviews, quantitative studies, or studies reporting on results of other studies. Studies undertaking mixed method research, however, were included, as they fulfilled the abovementioned criteria. All MMs and MBIs were included insofar as they incorporated mindfulness meditations. Studies only examining yoga were excluded.

The database search was conducted in March 2020. Three hundred sixteen articles and articles in press were found and served as a first set (see Fig. 1). The screening process was executed in March/April 2020 and June 2021 (for review) by the second author and a student assistant, and verified by the first author. The screening was based on article abstracts insofar as they provided the required information. If this was not the case, the full article was consulted. This process led to a second set of 241 articles. During the data analysis another 12 articles were excluded, either because it turned out they did not fit into the coding or the full article could not be found. In total, 229 articles were analyzed (see Supplementary Materials).

Fig. 1 Procedure of the SLR

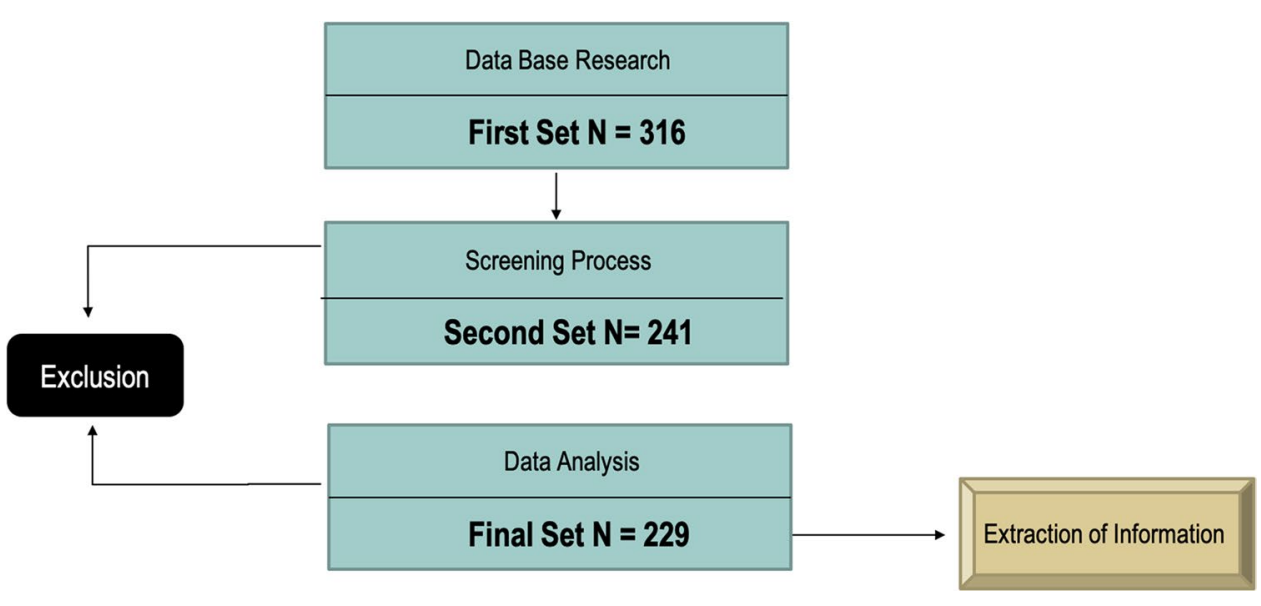




\section{Data Analyses}

The final set of articles was analyzed with regard to the following questions: When was the article published? Which journal was the article published in? Which discipline is the article attributed to? Which type of mindfulness practice was examined? What was the research interest of the study? What was the sample size? Who were the participants of the study? Which method was used for data collection? Which method was used for data analysis?

Dates of publication, disciplinary background, and journal information were retrieved directly from SCOPUS. The categorization of mindfulness practices followed Chiesa and Malinowski's (2011) distinction between MBIs and MMs and used the most popular forms of these practices as deductive categories (MBSR, MBCT, Vipassana, Zen). Further practices were inductively created. Also for the other questions, inductive codes were generated in an iterative process in order to capture the range of answers provided in the studies (see Supplementary Materials). With the help of this coding scheme, the full articles were systematically coded by the authors. The extracted information was then synthesized and quantitatively evaluated using Excel and SPSS.

\section{Results}

\section{Quantitative Development of QMPR}

Figure 2 shows the development of the quantity of published QMPR over the course of the last 20 years. Since 2010, the number of studies has grown each year, reaching a total number of 42 published articles in 2019. As shown in Fig. 3, absolute numbers of published articles are, however, still fairly low. In 2019, QMPR did not even constitute $10 \%$ of the yearly publications on the topic (despite the many open issues mentioned in the introduction) and has barely intensified in proportion to other (e.g., quantitative) methodical approaches.

\section{Disciplinary Research Background}

Figure 4 displays the disciplinary background to which the articles were attributed following the classification by SCOPUS. It is noteworthy that articles can be ascribed to multiple disciplines. For this reason, the number of the disciplines does not add up to 229. As is the case for general mindfulness research, QMPR was conducted in a broad scope of research fields. Most of the articles originated from the field of medicine (118 articles), followed by psychology (105 articles), and social science (75 articles). Mindfulness practice also received some interest in nursing research (37 articles). Only a few studies were assigned to the fields of arts and humanities (15 articles), health professions ( 9 articles), mathematics (4 articles), neuroscience (4 articles), and other disciplines (biochemistry, genetics, molecular biology, business management, and accounting, 8 articles in total).

In line with the variety of disciplinary backgrounds, QMPR was published in a large number of peer-reviewed journals. As shown in Table 1, the 229 articles found were published in 134 different journals. The majority of journals only published articles in the respective field once (106 journals) or twice (16 journals, marked gray). Only 12 of the journals included articles more than twice (marked light blue), with Mindfulness accounting for the most published articles on QMPR (44 articles), followed by the Journal of
Fig. 2 Published articles on qualitative mindfulness practice research, 2001-2019

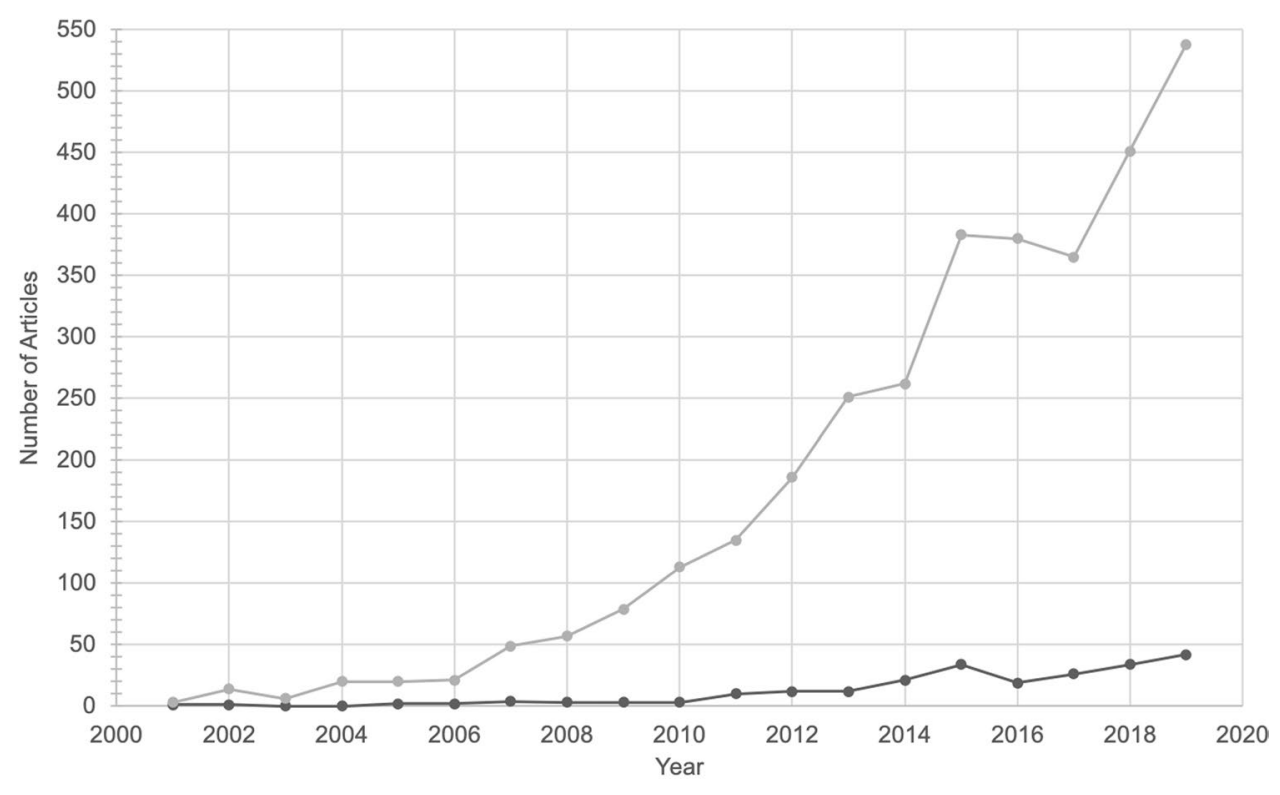

$\rightarrow-$ Number of Articles 'Qualitative Mindfulness Studies' $\rightarrow-$ Number of Articles 'Mindfulness Studies' 
Fig. 3 Published articles on QMPR and general publication trends on mindfulness practice, 2001-2019

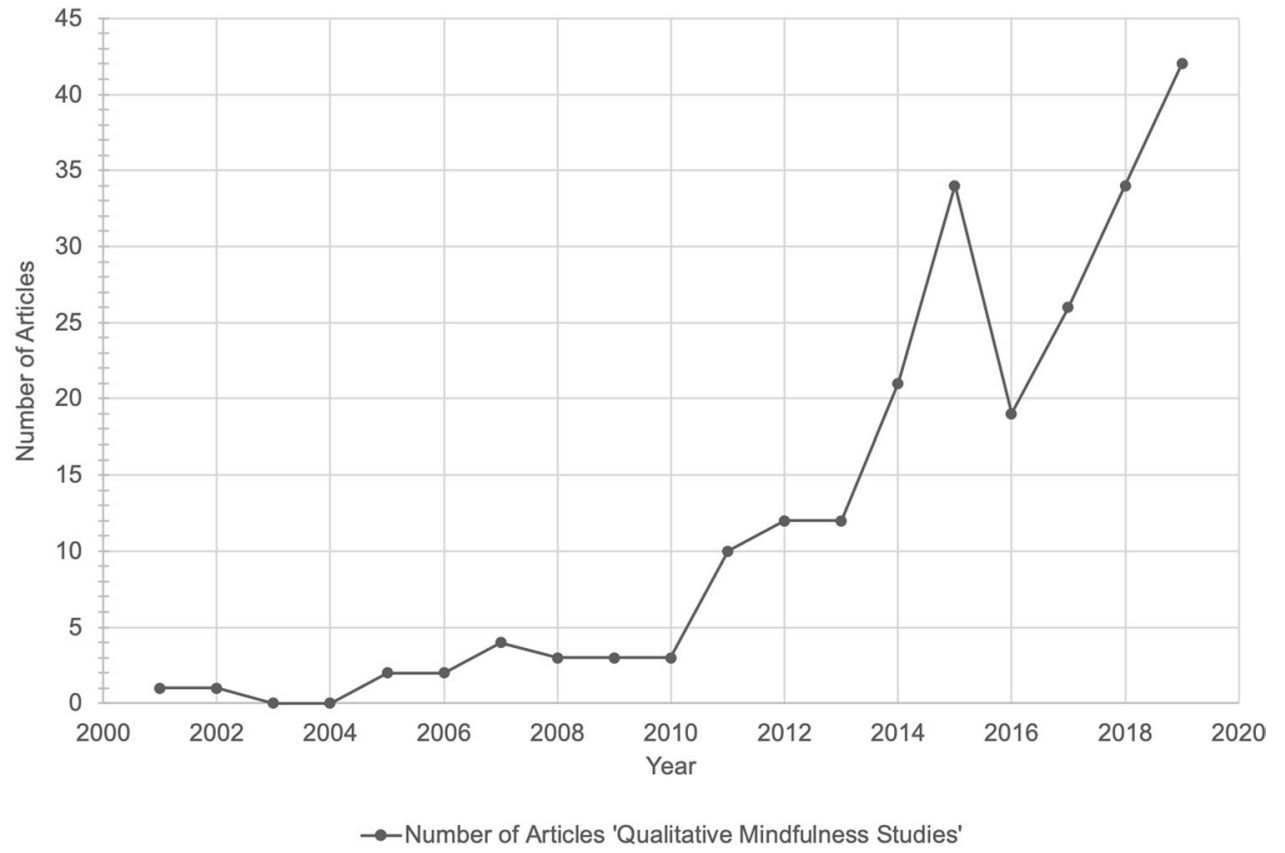

Alternative and Complementary Medicine (7 articles), and Complementary Therapies in Clinical Practice (6 articles).

Taking a closer look at the journals publishing QMPR allows for a more nuanced overview of the different topics under inquiry. The vast majority of the journals were dedicated to medical (including nursing) or psychotherapeutic research, albeit covering a large variety of subdisciplines (e.g., geriatrics, palliative medicine, psychiatry, gerontology, or oncology), pathologies (e.g., attention disorders, Alzheimer's disease, alcoholism, pain, or cancer), and target groups (e.g., military medicine, offender therapy, family therapy, sexual and relationship therapy, or children and adolescents). Closely related to and often intersecting with medical research were psychological journals, although not all of them had an explicit clinical or therapeutic focus (e.g., Personality and Individual Differences, Psychology of Sport and Exercise). Nine articles appeared in journals focusing on education, often associated to health-related education (BMC Medical Education, British Journal of Music Education, Education Research International, International Journal of Sustainability in Higher Education, Journal of Continuing Education in the
Fig. 4 Disciplinary background of published QMPR articles
140

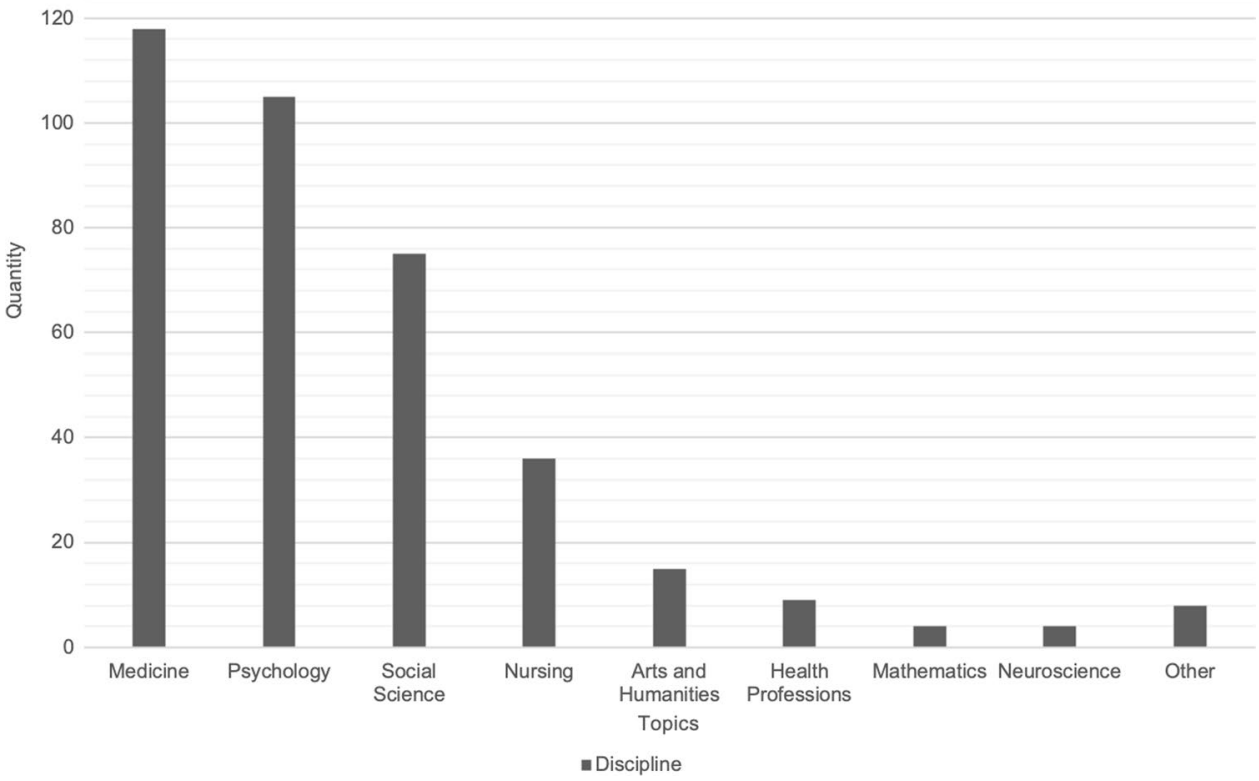


Table 1 Journals publishing QMPR
Academic Medicine (1)

Activities, Adaptations and Aging (1)

Advances in School and Mental Health

Promotion (1)

Advances in Mental Health and

Intellectual Disabilities (1)

Aging and Mental Health (3)

AIDS and Behavior (2)

Alcoholism Treatment Quarterly (1)

Annals of New York Academy of

Science (1)

Anthropology of Consciousness (1)

Archives of Women's mental health (2)

Art Therapy (1)

Australasian Psychiatry (1)

Australian Psychologist (1)

Australian Social Work (1)

Behavioral Medicine (1)

Behavioural and Cognitive

Psychotherapy (1)

BMC Geriatrics (1)

BMC Medical Education (1)

BMC Palliative Care (1)

BMC Psychiatry (2)

BMC Psychology (1)

BMJ Open (2)

BMJ Open Respiratory Research (1)

BMJ Quality and Safety (1)

British Journal of Clinical Psychology (1)

British Journal of General Practice (1)

British Journal of Medical Psychology

(1)

British Journal of Music Education (1)

Cancer Nursing (2)

Child and Adolescent Mental Health (3)

Chronic Respiratory Disease (1)

Clinical Child Psychology and

Psychiatry (2)

Clinical Psychologist (1)

Clinical Psychology and Psychotherapy

(2)

Cogent Social Sciences (1)

Cognitive Behaviour Therapist (4)

Collegian (1)

Community Mental Health Journal (1)

Complementary Therapies in Clinical

Practice (6)

Complementary Therapies in Medicine

(2)

Contemporary Buddhism (2)

Contemporary Family Therapy (1)

Contemporary Nurse (1)

Counselling and Psychotherapy Research

(1)

Counselling Psychology Quarterly (1)

Crisis (1)

Education Research International (1)

European Journal of Integrative

Medicine (1)

European Journal of Psychotherapy and

Counselling (1)

Evidence-Based Complementary and

Alternative Medicine (1)

Health Professions, Journal of Nursing Education, Journal of Transformative Education, Nurse Education Today, Teacher Development, Teachers College Report). Miscellaneous journals publishing QMPR included Contemporary Buddhism and the International Journal of Transpersonal Studies (2 articles respectively), the Annals of New York Academy of Science, Cogent Social Sciences, Australian Social Work, Geografiska Annaler, Series B: Human Geography, Journal of Social Service Research, Journal of Counseling and Development, Reading and Writing

\section{Explore: The Journal of Science and $\quad$ Journal of Holistic Nursing (3)}

Healing (2)

Journal of Humanistic Psychology (1)

Journal of Marital and Family Therapy (1)

Frontiers in Psychology (2)

Geografiska Annaler, Series B: Human Geography (1)

Health Promotion International (1)

Health Promotion Journal of Australia

(1)

Health Psychology and Behavioral

Medicine (1)

Health Technology Assessment (1)

Holistic Nursing Practice (2)

Humanistic Psychologist (1)

Infant Mental Health Journal (1)

Integrative Cancer Therapies (1)

International Journal for Medical

Informatics (1)

International Journal of Mental Health

and Addiction (1)

International Journal of Offender

Therapy and Comparative

Criminology (1)

International Journal of Qualitative

Studies on Health and Well-being (1)

International Journal of Stress

Management (1)

International Journal of Sustainability

in Higher Education (1)

International Journal of Transpersonal

Studies (2)

International Journal of Workplace

Health Management (1)

Japanese Journal of Clinical Oncology

(1)

Journal for Marital and Family

Therapy (1)

Journal of Adolescent and Young Adult

Oncology (1)

Journal of Adolescent Health (1)

Journal of Alternative and

Complementary Medicine (7)

Journal of Alzheimer's Disease (1)

Journal of Applied Gerontology (1)

Journal of Attention Disorders (1)

Journal of Child and Family Studies

(2)

Journal of Clinical Sport Psychology

(1)

Journal of College Student

Psychotherapy (1)

Journal of Continuing Education in the

Health Professions (1)

Journal of Counseling and

Development (1)

Journal of Endometriosis (1)

Journal of Evidence Based

Complementary and Alternative

Medicine (1)

Journal of Evidence-Based Integrative

Medicine (1)

Journal of Gerontological Social Work (1)

Journal of Health Psychology (1)

Journal of Nursing Education (1)

ournal of Pain (1)

Journal of Pain Management (1)

Journal of Pediatrics (1)

Journal of Pediatric Nursing (1)

Journal of Pediatric Oncology Nursing

(1)

Journal of Police and Criminal

Psychology (1)

Journal of Psychosomatic Research (2)

Journal of Racial and Ethnic Health

Disparities (1)

Journal of Religion and Health (1)

Journal of Religion and Spirituality in

Social Work (3)

Journal of Social Service Research (1)

Journal of Transformative Education (1)

Mental Health, Religion and Culture (1)

Military Medicine (1)

Mindfulness (44)

Neuropsychological Rehabilitation (1)

Nurse Education Today (1)

Nursing Open (1)

Pain Management Nursing (1)

Pain Medicine (1)

Palliative and Supportive Care (1)

Palliative Medicine (2)

Pediatric Cardiology (1)

Personality and Individual Differences

(1)

Pilot and Feasibility Studies (2)

PLoS ONE (3)

Primary Health Care Research and

Development (1)

Psycho-Oncology (1)

Psychology and Psychotherapy: Theory,

Research and Practice (1)

Psychology of Sport and Exercise (1)

Psychotherapy Research (3)

Qualitative Health Research (1)

Reading and Writing Quarterly (1)

Sexual and Relationship Therapy (2)

Smith College Studies in Social Work (1)

Social Science (1)

Social Science in Health Care (1)

Stress and Health (1)

Supportive Care in Cancer (3)

Teacher Development (1)

Teachers College Record (1)

Therapeutic Communities (1)

Western Journal of Nursing Research (1)

Quarterly, or Social Science (1 article each). These numbers confirm that mindfulness practice has entered a large variety of academic disciplines and professional contexts.

\section{Types of Mindfulness Practice}

In regard to the type of mindfulness practice underlying QMPR, we applied the following categorization: If the article explicitly aimed to investigate MBSR, MBCT, adapted MBSR/MBCT, MATs, Zen, Vipassana, or mindfulness 
practice teacher trainings, we assigned it to one of those categories. Studies that were attributed to the category "other MBIs" examined a mindfulness intervention that was different from MBSR, MBCT, or MAT, yet provided a full description of the program structure and content. Interventions that are associated with this category were called, for example, My Mind Course, 4-Week Mindful Transition to Parenthood Program, Mindfulness-Based Substance Use Intervention, 6 Week Mindfulness-Based Lifestyle Program, or Mindful Mood Balance. Analogously, the category "other MMs" subsumed practices other than Zen or Vipassana that were labeled mindfulness meditations and included a full description of the practice under investigation. The category "mindfulness practice not specified," finally, included those articles that explicitly aimed to explore an MBI or MM, but did not fully specify the practice (e.g., not fully exposing the content and structure of a course or a meditation practice).

The frequency of the mindfulness practices addressed in the articles is displayed in Fig. 5. In line with previous research, our results show that a significant portion of examined mindfulness practices were MBIs (178 articles, 78\%), particularly MBSR, MBCT, and adapted versions (127 articles, $\sim 55 \%$ ). However, new MBI formats were also frequently examined in QMPR research, constituting roughly one-fifth (45 articles) of all reviewed articles. MMs (Vipassana, Zen, and other MMs) showed a relatively low frequency among the studies ( 25 articles, $~ 11 \%$ ), with Vipassana and Zen meditation investigated in only 5 and 3 articles, respectively. Teacher trainings were rarely addressed in the sample, too (3 articles). Remarkably, more than one out of ten articles did not fully specify the mindfulness practice.

\section{Research Interest}

We also examined the different research interests mentioned in each study. Table 2 presents the categories that emerged, describing clusters of research interests and their frequency and distribution. The categories do not always represent distinct research interests. Attribution was based on the expressed research interest in the article. Moreover, articles were attributed to more than one category if several research interests were mentioned.

Figure 6 shows the frequency of research interests in the QMPR literature. The efficacy of mindfulness practice constituted the dominant interest of QMPR (122 articles, 53\%). These studies focused on specific effects (e.g., dealing with pain or stress, weight control, or understanding of mindfulness), inquired into the effectiveness of specific program adaptations, or looked at program effectiveness for specific populations (e.g., youth, employees, clinical populations). Another frequent research objective of QMPR was to reconstruct the subjective experience of practicing mindfulness (93 articles, 41\%). This included the intention to better understand the experience of specific aspects of the training or to identify mechanisms that underly reported training effects. Feasibility studies made up 24\% (55) of all articles. As is the case for efficacy studies, these articles usually focus on the feasibility of specific programs or established programs for specific populations. Forty-three articles $(\sim 19 \%)$ addressed participants' evaluations (acceptability) of mindfulness practices. Strikingly, a relatively small share of QMPR studies focused on barriers and facilitators (15 articles, 7\%), challenges and adverse effects (6 articles, $\sim 3 \%$ ), or factors influencing the practice experience
Fig. 5 Distribution of QMPR by mindfulness practice

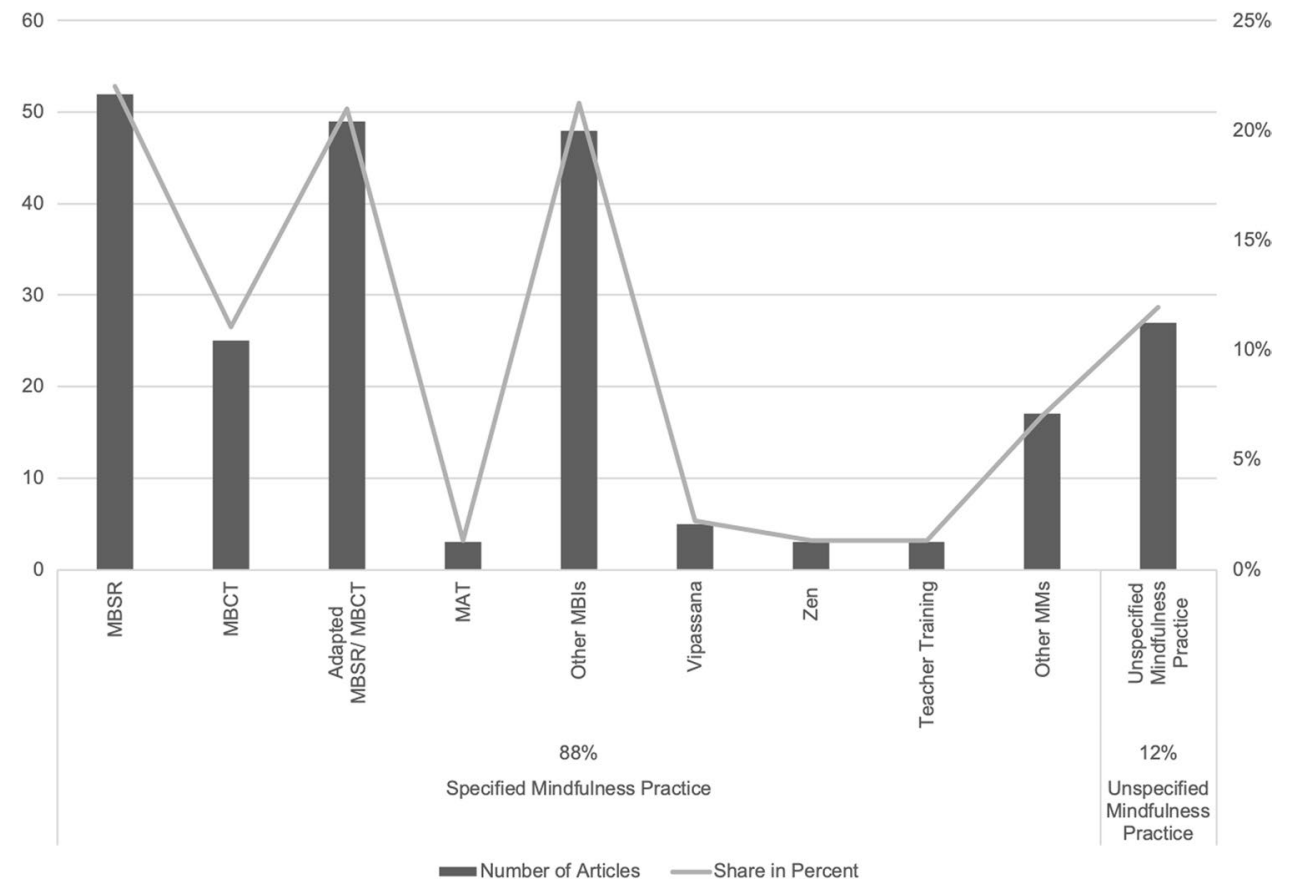


Table 2 Categories of research interests of QMPR articles

\begin{tabular}{ll}
\hline Research Question & Definition \\
\hline Efficacy & All cases exploring effects (benefits) of a mindfulness practice \\
$\begin{array}{l}\text { Acceptability } \\
\text { Feasibility }\end{array}$ & All cases exploring participants' evaluations of the mindfulness practice \\
Reflection of experiences & All cases exploring the feasibility of an intervention \\
& All cases that explore the reflection of the experiences of a mindfulness practice. It included \\
& studies asking the inquired subjects to reflect their experiences of a practice or reflect \\
working mechanisms & All cases examining factors influencing the experience of the mindfulness practice, such as \\
the impact of the group setting, prior knowledge of/experience with mindfulness practice, & \\
& or the role of the mindfulness teacher \\
Challenges and adverse effects & All cases exploring challenges occurring during and negative effects of mindfulness practice \\
Barriers and facilitators & All cases asking for the reasons to engage or not to engage in a mindfulness practice \\
Scale development/validation & All cases using qualitative research for scale development and validation \\
Comparison of methods & All cases aiming to compare qualitative research methods for inquiring mindfulness practice \\
\hline
\end{tabular}

(4 articles, 2\%). Only 2 articles used qualitative research for scale development and validation. One article compared strengths and weaknesses of qualitative methods when investigating mindfulness practice.

Figure 7 relates the type of mindfulness practice to the research interest. Three observations are striking in this chart: First, research conducted on MBSR, adapted MBSR, and other MBIs were primarily interested in the intervention's efficacy ( $75 \%$ percent of the studies addressing this research interest). Second, studies looking at MBCT programs and "Other MMs" showed a considerably higher interest in "reflection" than in the other research interests, representing $22 \%$ and $12 \%$ of all studies (in contrast to $11 \%$ and $7 \%$ of the overall distribution, Fig. 5). Third, while the distribution of mindfulness practices among studies interested in efficacy, acceptability, feasibility, and reflection still mostly reflected the overall frequencies displayed in Fig. 8, this was not the case at all when it came to other research

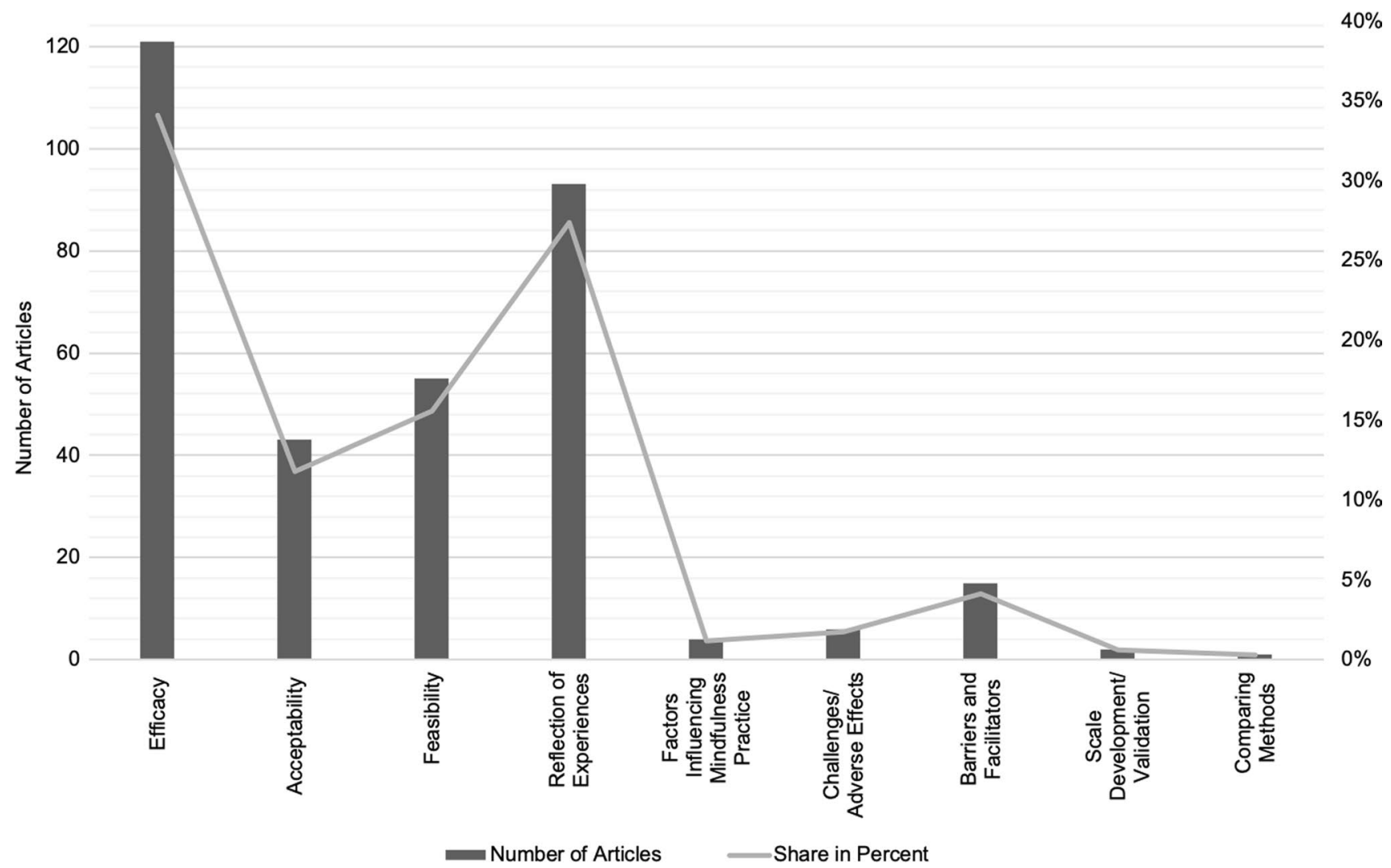

Fig. 6 Research interests of QMPR studies 


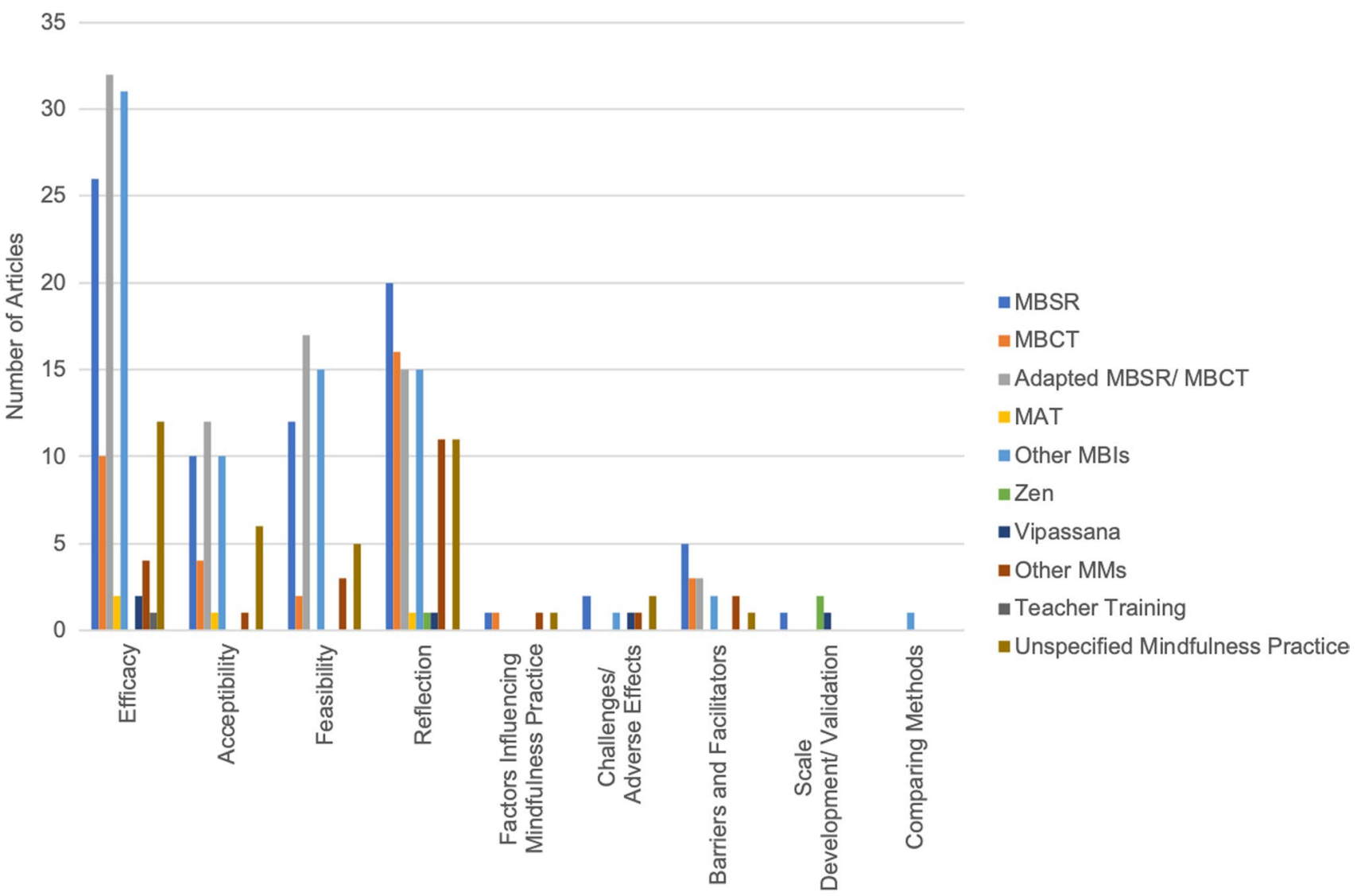

Research Interest

Fig. 7 Research interests in relation to mindfulness practice under inquiry

interests. Although these research interests received little attention across all mindfulness practices, Fig. 7 indicates that they remain particularly neglected in qualitative MBI research.

\section{Research Design}

Concerning the overall research design, two-fifths of all articles (89 out of 229) undertook mixed-method research (quantitative and qualitative methods) on mindfulness practice. One hundred forty articles (60\%) applied an exclusively qualitative research design (Table 3 ).

\section{Data Collection}

With regard to the data collection of the studies, we analyzed sample sizes, types of subjects providing the data, and the applied data collection methods. Concerning the types of subjects, we also analyzed to what extent the studies included dropouts or former practitioners in their data collectioni.
Sample Size Table 4 depicts the distribution of the studies over these categories (for the mixed-method studies, only the people inquired for the qualitative part were taken into account). Most studies had a sample size of 10-20 persons (85 articles). Sixty-one articles used a smaller sample of 1-10 subjects. Fifty-nine articles relied on a relatively big sample (20-50 subjects). Twenty-three studies collected data from more than 50 persons. One article did not state the size of the sample.

Types of Subjects We distinguished six types of subjects providing data for the studies from our sampling. Apart from (potential) practitioners, the category "Course Facilitators" included persons that are responsible for organizing or hosting a mindfulness practice, whereas "Trainer/Teacher" refers to the persons who led the mindfulness practice. Studies drawing on data from "observers" were based on impressions from external observers of a training, that is, they neither participated in nor led the training. The final category included "Persons of personal environment" (e.g., friends, family). Multiple answers were possible when studies included more than one type of subjects. 


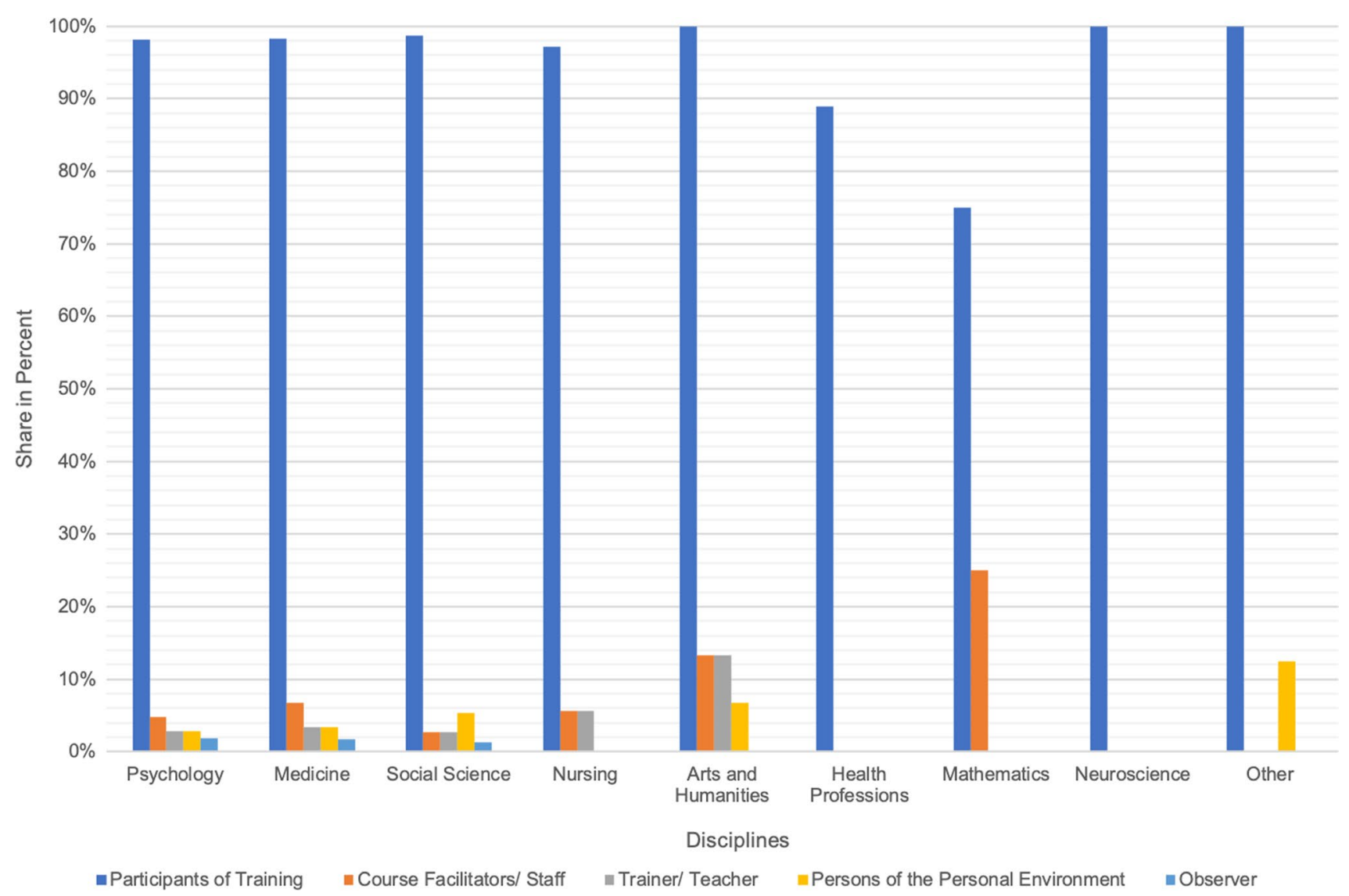

Fig. 8 Types of subjects in QMPR studies in relation to their disciplinary background

Table 3 Share of mixed-method research in comparison to purely qualitative studies

\begin{tabular}{lll}
\hline Research design & \# of articles & $\%$ of articles \\
\hline Mixed-method & 89 & $40 \%$ \\
Exclusively qualitative & 140 & $60 \%$ \\
\hline
\end{tabular}

Table 5 presents the frequency of the different types of subjects. Almost all articles $(n=227)$ relied on (potential) practice participants. A few studies included other types of subjects in addition to (potential) practitioners: 9 studies obtained information from course facilitators. The same amount of articles gathered impressions from the personal

Table 4 Sample sizes in QMPR

\begin{tabular}{lll}
\hline Sample size & \# of articles & $\%$ of articles \\
\hline $1-10$ & 61 & $27 \%$ \\
$10-20$ & 85 & $37 \%$ \\
$20-50$ & 59 & $26 \%$ \\
$>50$ & 23 & $10 \%$ \\
Not stated & 1 & $<1 \%$ \\
\hline
\end{tabular}

For the mixed-method studies, only the people inquired for the qualitative part were taken into account environment of practitioners (parents: 3 articles; partners: 2 articles; entire families: 2 articles; caregivers: 2 articles; music teachers: 1 article). Practice teachers were considered in 7 articles, while external observers (researchers: 2 articles; colleagues: 1 article) provided data in 3 studies. Relating the type of subject to the disciplinary background of the QMPR reveals that the strong focus on practice participants is common among all academic disciplines (see Fig. 11).

Dropout Inclusion In addition to the types of subjects, we checked whether the analyzed studies included dropouts or former meditation practitioners (i.e., individuals who previously engaged in mindfulness practice yet decided to skip the practice). One hundred seventy-eight articles from our sample were eligible for this inquiry, as they drew on

Table 5 Types of subjects in QMPR studies

\begin{tabular}{lll}
\hline Type of subjects & \# of articles & $\%$ of articles \\
\hline Participants of practice/practicioners & 227 & $99 \%$ \\
Course facilitators & 9 & $4 \%$ \\
Trainer/teacher & 7 & $3 \%$ \\
Observer & 3 & $1 \%$ \\
Persons of personal environment & 9 & $4 \%$ \\
\hline
\end{tabular}


individuals who had already participated in an MBI or practiced some form of MM.

Forty-nine articles did not report any dropouts (these include studies in which it was not possible to drop out, e.g., mandatory school interventions). Thirty-eight articles did not provide information about dropout rates. The remaining 104 articles either indicated dropout rates or were based on samples that potentially included dropouts or former meditation practitioners. Out of these 104 articles, 76 articles (73\%) did not include such subjects; 10 articles (10\%) collected data from dropouts or former meditation practitioners. Eighteen articles (17\%) did not provide clear information as to whether these subjects were included in the data collection (Table 6).

Data Collection Methods The scoping review revealed that most studies used questionnaires and surveys, interviews, focus groups, diaries, and reports as data collection methods. The category "Other" included video and audio recordings of sessions, as well as notes of mindfulness teachers participating in practice sessions. Many studies used more than one data collection method, and accordingly, they were assigned to more than one category.

The results on data collection methods are shown in Table 7. The majority of studies used "Interviews" (58\%, 162 articles) to collect data. Less frequently applied methods included questionnaires or surveys (16\%, 45 articles), followed by focus groups (15\%, 42 articles), diaries or reports (10\%, 28 articles), or other methods ( 3 articles in total, with 1 using video recordings, 1 audio recordings, and 1 notes by mindfulness teachers). One article did not state the data collection method. As Fig. 9 shows, this distribution can be found beyond disciplinary boundaries in QMPR. It is worth mentioning that about a quarter of all studies combined data collection methods (87 articles in total). Combining interviews with focus groups, questionnaires, and/or diaries appeared to be the most popular form of qualitative data triangulation.

Figure 10 correlates the data collection methods with the research interests guiding the studies. The previously described frequencies also apply to the four predominant

Table 6 Share of studies including dropouts and former mindfulness practitioners as subjects

\begin{tabular}{lll}
\hline Dropout inclusion & \# of articles & $\%$ of articles \\
\hline Dropouts included & 10 & $10 \%$ \\
No dropouts included & 76 & $73 \%$ \\
Unclear & 18 & $17 \%$ \\
\hline
\end{tabular}

Based on 104 articles that either indicated dropout rates or were based on samples that potentially included dropouts or former meditation practitioners
Table 7 Data collection methods in QMPR studies

\begin{tabular}{lll}
\hline Method & \# of articles & $\%$ of articles \\
\hline Interview & 162 & $58 \%$ \\
Questionnaire/survey & 45 & $16 \%$ \\
Focus group & 42 & $15 \%$ \\
Diary/report & 28 & $10 \%$ \\
Other & 3 & $1 \%$ \\
Not stated & 1 & $<1 \%$ \\
\hline
\end{tabular}

research interests ("efficacy," "acceptability," "feasibility," "reflection"), with interviews being the most frequently used data collection method by far. Studies interested in individuals' reflections on mindfulness practice were particularly prone to collect data using interviews $(\sim 82 \%)$. Given that studies dedicated to the other research interests are scarce and make up less than $8 \%$ of the total number of studies, the relative distribution of data collection methods is inconclusive. Nevertheless, the results suggest a potential to apply data collection methods other than interviews when addressing these research questions.

Data Analysis In a next step, we analyzed the different methods applied for data analysis within our sample. Whenever a method was observed more than once, we added a category for this method. We assigned all articles that followed a grounded theory methodology to the category "Grounded Theory," without further distinguishing between different grounded theory approaches (e.g.Charmaz, 2000; Clarke, 2005; Corbin \& Strauss, 2008; Glaser, 1992). The "Content and Thematic Analyses" category included approaches such as framework analysis (Ritchie \& Spencer, 1994) or template analysis (Brooks \& King, 2012) as two subtypes of thematic analysis. The "Interpretative/Descriptive Phenomenological analysis" category included articles applying either interpretative phenomenological analysis (Smith \& Osborn, 2008) or descriptive phenomenological analysis (Giorgi, 2009). If a method was only applied once, articles were assigned to the category "Other." If analytical approaches were combined in a study, it was included in the category "Pluralistic Qualitative Research." Studies that did not provide sufficient information about the methodical procedure categorized as "not specified."

Table 8 depicts the distribution and relative frequencies of the data analysis methods. Content and thematic analyses were by far the most frequently applied method in QMPR (141 articles, 60\%). Grounded theory (27 articles, 11\%) and phenomenological approaches (21 articles, 9\%) made up a significantly smaller share. A closer look at studies claiming to conduct grounded theory research also revealed that the actual inquiry often seemed only inspired by this approach and was restricted to (parts of) the data analysis. Although grounded theory is characterized by an iterative process of 


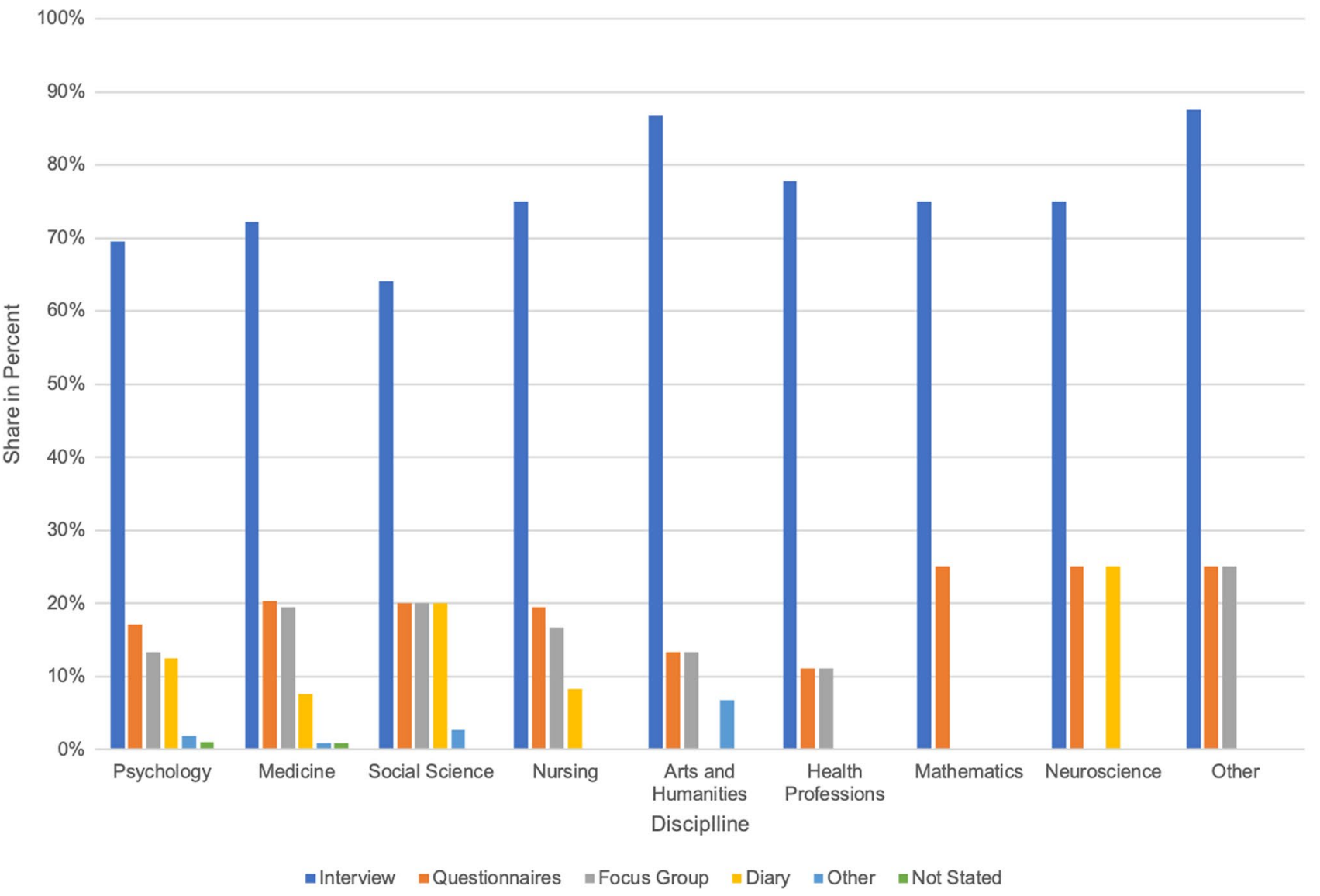

Fig. 9 Data collection methods in relation to their disciplinary background

data collection and analysis (Corbin \& Strauss, 2008), the majority of studies applying grounded theory in our sample were limited to (elements of) the coding procedure and the process of constantly comparing interim findings. The analysis was most frequently undertaken once the data collection has already taken place. 5 articles (2\%) were assigned to the category "Other." These articles used relational-centered research (Finlay \& Evans, 2009), case study research (Yin, 2013), auto-ethnography (Ellis, 2004), discourse analysis (Keller, 2011), and integrative interview analysis (Helfferich \& Kruse, 2007). Only three articles combined qualitative analytical methods. Strikingly, almost one out of five articles (39 articles, $17 \%$ ) did not describe or fully specify the data analysis. In many cases, articles refer to constant comparative analysis (Hewitt-Taylor, 2001) when outlining the analytical process. However, constant comparison rather describes a specific technique of qualitative research that can be integrated into different methods but does not represent an independent method. The same can be said about line-by-line coding, which was also mentioned as a method of data analysis.

We also related the analytical approaches to the disciplines and research interests underlying the QMPR. As depicted in Fig. 11, the overall tendencies for data analysis in QMPR can be found across disciplines. In all disciplines, content and thematic analyses were by far the most frequently used methods for data analysis, followed by grounded theory. The figure also makes clear that an incomplete description of the analytical procedure is not exclusive to certain disciplines, but can be observed beyond disciplinary boundaries.

When relating analytical methods to the underlying research interests, the distribution resembled the one discussed above (Fig. 12). Content and thematic analyses were applied in more than $60 \%$ of the studies addressing the most popular research questions ("efficacy," "acceptability," "feasibility," "reflection"). Strikingly, studies looking at the efficacy, acceptability, feasibility, as well as challenges and adverse effects of mindfulness practice were particularly prone to not fully disclosing the analytical procedure. The relative distribution of data analysis methods in relation to the research interests was by no means conclusive due to the low number of studies dedicated to these interests. As was the case for data collection, however, the results suggested that the use of methods for data analysis was rather limited across research interests. 


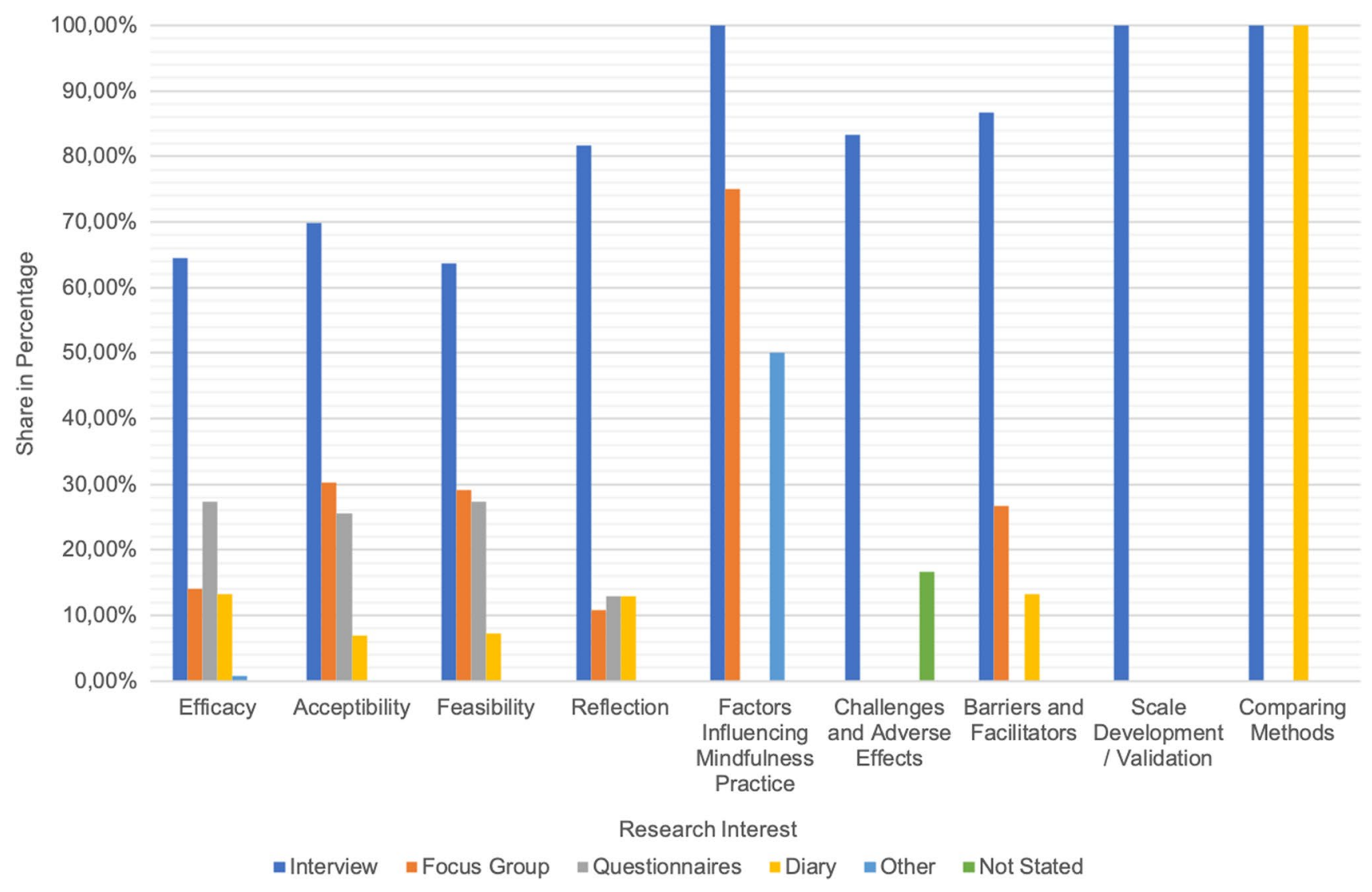

Fig. 10 Data collection methods in relation to research interests

Data Analysis and Research Teams The final interest of our review was to inquire whether the data analyses were undertaken by one researcher or research teams (more than one researcher). If the latter was the case, we looked at the composition of the research teams. As shown in Table 9, roughly one-third (82) of the articles considered in our review did not provide any information as to whether one or more persons were involved in the data analysis. Two articles explicitly stated that only one researcher was responsible for data analysis. In the majority of studies (parts of the), data analysis was undertaken by more than one researcher $(63 \%, 145$ articles). However, there were strong differences in the composition of research teams concerning data analysis and the role the members played in this process: First, the number

Table 8 Share of analytical approaches among QMPR studies

\begin{tabular}{lll}
\hline Approach & \# of articles & $\%$ of articles \\
\hline Content analysis/thematic analysis & 141 & $60 \%$ \\
Grounded theory & 27 & $11 \%$ \\
Interpretative/descriptive phenomeno- & 21 & $9 \%$ \\
$\quad$ logical analysis & & \\
Other & 5 & $2 \%$ \\
Pluralistic qualitative research & 3 & $1 \%$ \\
Not stated & 39 & $17 \%$
\end{tabular}

of members varies strongly among studies (from 2 up to 8), with 2 or 3 members being the most widespread composition (63 and 36 articles, respectively). Second, the role of these members in the analysis process was very different. While members equally participated in all steps of the process in some studies, additional researchers only participated in the coding process of data or simply supervised (parts of) the analytical process in the majority of studies. Third, the background of the members varied strongly in-between studies. The vast majority of analyses were undertaken by researchers with the same disciplinary background. In some cases, independent students (4 articles) or fellow researchers (7 articles) participated in some way or another (e.g., theme validation, interpretation groups) in the data analysis. Non-academic experts (e.g., psychotherapists, mindfulness trainers) or course participants were only rarely involved in this process (4 articles).

\section{Discussion}

QMPR has grown in the last decades, although this increase is not in proportion to the rapidly growing number of publications on mindfulness in general. The majority of QMPR 


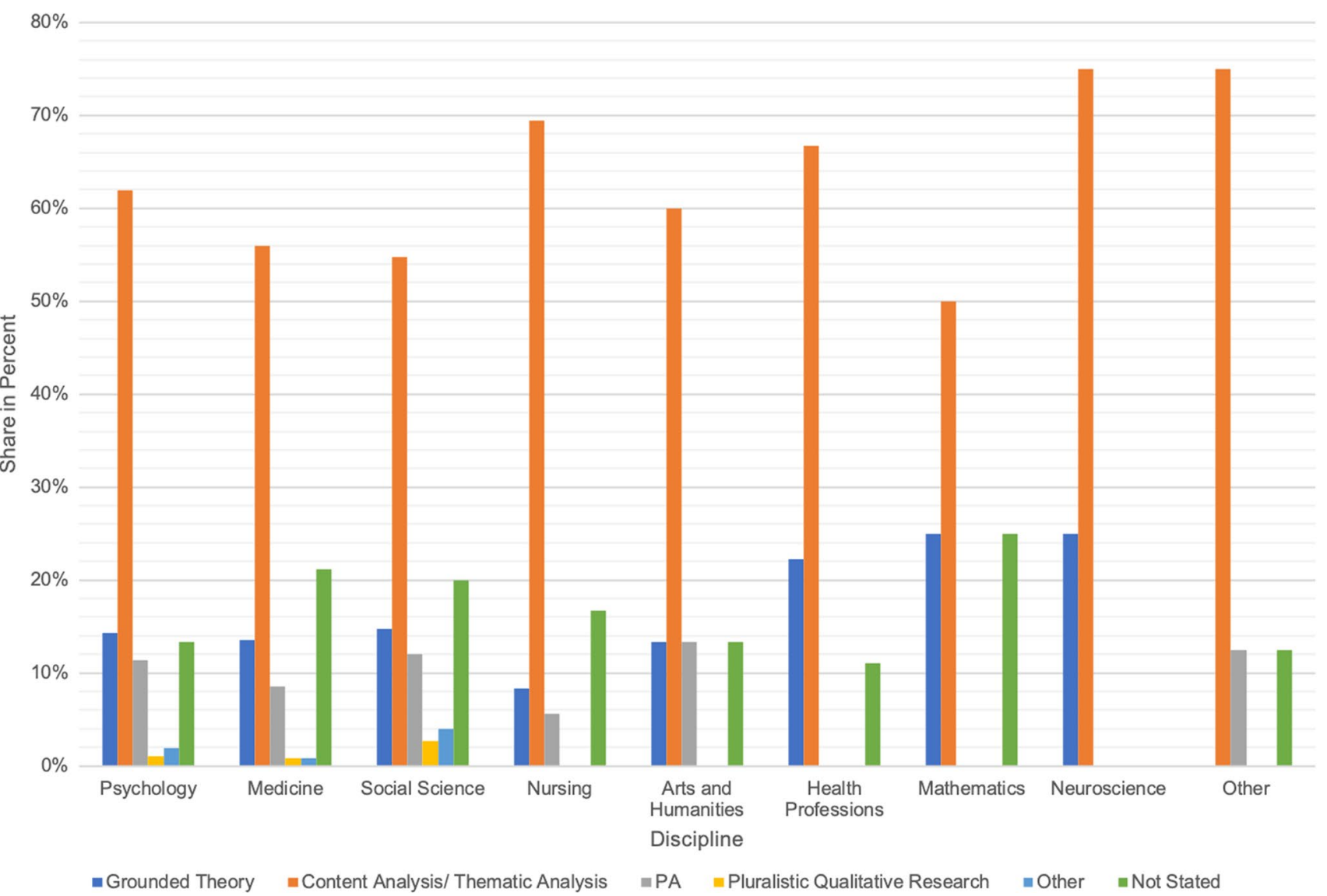

Fig. 11 Analytical approaches in relation to their disciplinary background

publications stemmed from medical research. Mindfulness was by far the most popular journal for publishing QMPR, although corresponding articles were occasionally published in a wide range of scientific journals across disciplines.

In terms of the types of practices QMPR inquiry emphasizes, we found a strong focus on MBIs, particularly MBSR, MBCT, and adaptations. MMs were far less frequently the object of QMPR. Strikingly, more than one out of ten articles did not fully specify the mindfulness practice, that is, the article left out relevant information about the content, structure, or duration of the practice. Teacher trainings were barely investigated in the articles considered in this review.

Regarding the research interest of QMPR, the efficacy and participants' reflections on the practice experience were the most prominent. Although qualitative studies also shed light on the feasibility and acceptability of mindfulness practices and occasionally inquired into adversarial effects, our review revealed that studies tended to emphasize the benefits of mindfulness practice. Data collection was highly concentrated on (potential) practice participants and relied first and foremost on first-person data. Second or third-person data, in contrast, was barely collected by studies included in our sample. The majority of studies did not consider dropouts or former mindfulness practitioners for their data collection.
Concerning data analysis, the scoping review showed that interpretative methods (primarily content/thematic analyses) were the predominant approach within QMPR. While grounded theory was also frequently used, its application was usually restricted to (parts of) the data analysis and its epistemic potential hence not fully unleashed. Pluralistic qualitative approaches were very scarce. Seventeen percent of all articles considered for our study did not fully disclose their analytical procedure. Moreover, details on the composition of research teams were often missing, and heterogeneous teams for data analysis were the exception rather than the norm.

In light of the concerns and suggestions expressed regarding current mindfulness research (see Introduction), these findings indicate that QMPR has so far not unleashed its full potential to address problems revolving around mindfulness research and advance the understanding of the field. Undoubtedly, the results show that QMPR contributes to a more nuanced understanding of the subjective experiences of mindfulness practice as well as the identification of mechanisms that explain these experiences. Understanding these subjective experiences is particularly useful when looking at new or adaptations of established MBIs or delivering mindfulness practices to specific populations, both constituting 
$120 \%$

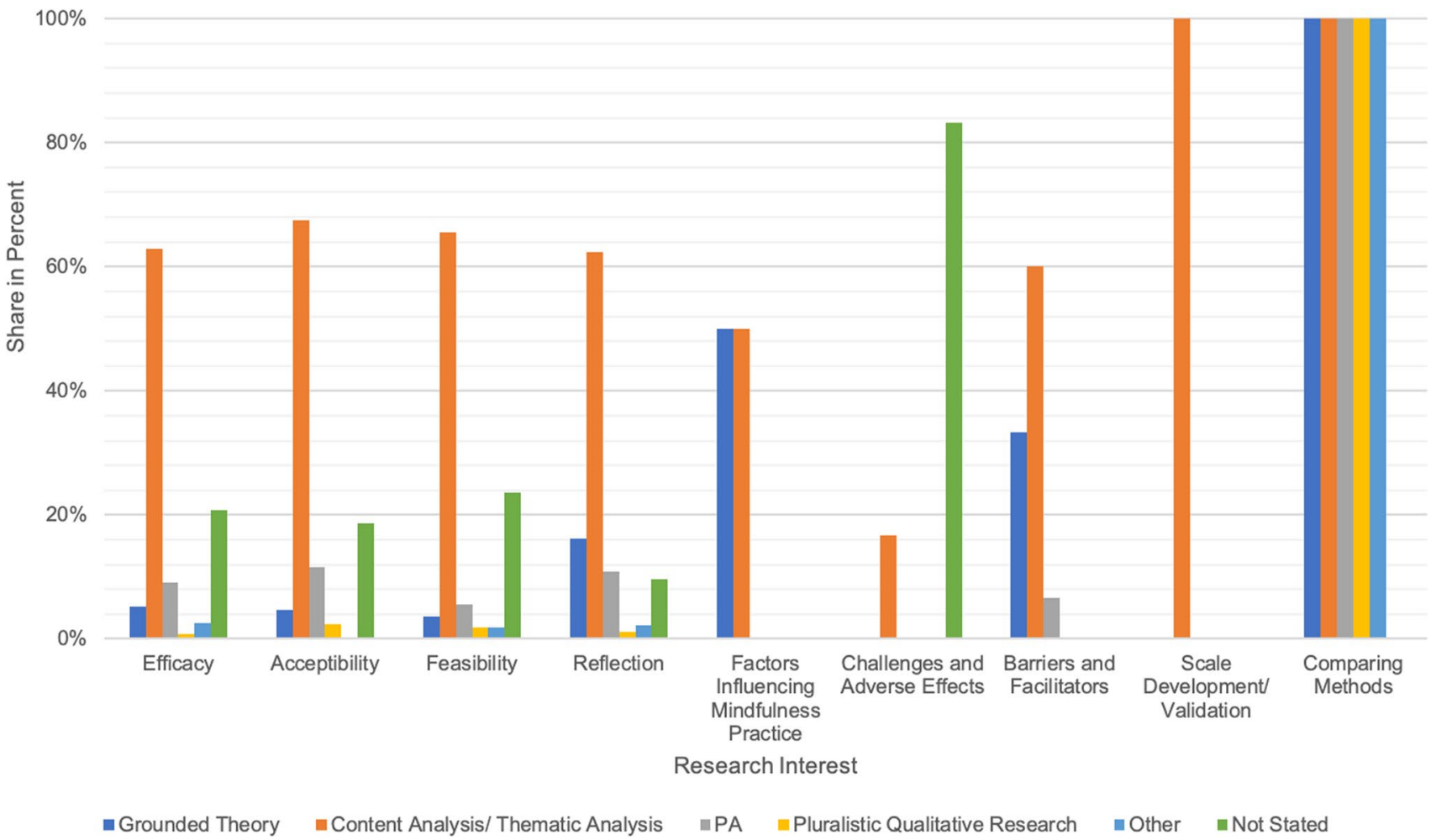

Fig. 12 Analytical approaches in relation to research interests

important fields of inquiry of QMPR. Moreover, qualitative studies have focused on factors influencing the practice experience, such as the role of the trainer and course facilitator, contextual factors, or practitioners' expectations toward the practice. Studies investigating potential harm, adverse effects, and limitations of mindfulness practice have also been conducted, demonstrating that QMPR has responded to calls for such kind of research (e.g., Krägeloh et al., 2019; van Dam et al., 2018).

Nevertheless, the findings also demonstrate that QMPR is not per se sufficient to overcome the problems characterizing large parts of current mindfulness research. In fact, QMPR shares many of the shortcomings of general mindfulness research, namely the strong reliance on participants' self-reports, lack of specificity when describing practices under investigation, the overemphasis on (positive) effects

Table 9 Share of QMPR studies in which data analysis was conducted by research teams

\begin{tabular}{lll}
\hline Research team & \# of articles & $\%$ of articles \\
\hline Yes & 145 & $63 \%$ \\
Not indicated & 82 & $36 \%$ \\
No & 2 & $1 \%$ \\
\hline
\end{tabular}

experienced by mindfulness practitioners, and the tendency to exclude dropouts. This is also reflected in the significantly lower number of studies looking at limitations, harm, and adverse effects of the practice-even though these issues are equally relevant when inquiring into new or adaptations of established forms of practice, or working with specific populations. Certainly, the tendency to primarily report positive effects of mindfulness practice can have several reasons, including, for example, that the practice itself might change the perspective on subjectively experienced challenges and difficulties in a positive way (Malpass et al., 2019). It might also be that people who dislike the practice or make negative experiences are less willing to participate in QMPR, which can also explain why dropouts were far less frequently included in our study sample. At the same time, the positivity bias (Nowogrodzki, 2016) might also be the result of mindfulness researchers' sympathy for the practice and their interest in promoting them. Qualitative researchers relying on interpretations should arrange their research design in such a way that these proclivities can be avoided or at least reflected.

What is most striking about our findings, howeverand this is where QMPR's potential is far from being unleashed-is the narrow method(olog)ical focus of current 
QMPR. Our results reveal at least three manners in which this narrow focus manifests itself. First, interpretive-constructionist paradigms strongly dominate the data analyses applied in QMPR. Studies fully applying grounded theory (which incorporate an iterative data collection and analysis) are rare. Almost non-existent so far are discourse analytical approaches toward mindfulness practice and conversation analyses, although these could have a great potential especially for identifying limitations and adverse effects of the practice (Frank et al., 2019; Wooffitt \& Holt, 2011). Second, pluralistic qualitative research is also rare in QMPR, despite scholars' recommendations to conduct multimodal research (van Dam et al., 2018). Frank et al. (2019) have exemplified how "a pluralistic qualitative research assists in identifying blind spots and limitations of a single method, increases the self-reflexivity, and helps to arrive at a more comprehensive understanding of mindfulness practice or other processes of covert lived experience" (p. 2452). Despite such recommendations and examples, pluralistic qualitative research remains scarce among QMPR publications. Third, QMPR barely makes use of adversarial collaboration when inquiring into mindfulness practice, although qualitative methods are well suited for and explicitly encourage such collaboration (e.g., Reichertz, 2013). On top of these limitations, we identified shortcomings in precisely disclosing the applied analytical procedure, including its underlying ideological, epistemological, and ontological assumptions. While the disclosure of these assumptions has been repeatedly identified as the central quality criteria of qualitative research and has become common sense in other disciplines, such as educational research (DeJaeghere et al., 2019), it does not seem to be common practice in QMPR yet.

We think that future QMPR, and mindfulness research more generally, would greatly benefit from addressing these limitations. Fully disclosing details on the mindfulness practice should be a basic feature of quality studies. It is crucial both for other researchers and practitioners to know about the specific activities that constitute the basis for one's research. Similarly, QMPR (as with any kind of (qualitative) research) should be fully transparent about the methods applied and their underlying assumptions. Again, this is a general qualitative indicator for any kind of research, helping to avoid and better understand the limitations of a specific study while indicating the researchers' reflection about their work and their role in it.

Adversarial research teams could further contribute to increasing the reflexivity of a study. More importantly, these interactions might allow researchers to critically engage with their assumptions about what mindfulness practice could and should do, which can be particularly important if researchers have a favorable opinion of the practice. Especially analyzing qualitative data describes a process that is unavoidably influenced by the subjective interpretations of those conducting the study (e.g., Mruck \& Breuer, 2003). Building entire research projects around adversarial research teams even goes a step further, because doing so could reduce bias when it comes to the overall research interest, research design, and data collection procedure from the very beginning, hence increasing (critical) self-reflection throughout the entire research process.

Conducting pluralistic qualitative research can be another way to address these biases while providing a means to overcome the limitations of singular qualitative approaches. Such pluralistic approaches allow for the integration of different epistemological, ontological, and methodological perspectives, thereby preventing an overemphasis on potentially desired outcomes (e.g., positive effects) or superficial and incomplete interpretations of one's findings. Given the tendency of mindfulness research to overemphasize positive results (Nowogrodzki, 2016), pluralistic qualitative research, then, could be a way to reintroduce a critical perspective that systematically increases self-reflection in QMPR.

Combining multiple (qualitative) research approaches is also compatible with diversifying the types of data. To better understand the effects of a mindfulness practice, for example, future studies should also consider the perspectives of mindfulness teachers, family members, or friends and not just relying on participants' self-reports. This is especially important if the anticipated effects are socially desirable (e.g., pro-social behaviors, pro-environmental behaviors), as most people want to be seen and tend to think of themselves as moral beings while overlooking or withholding thoughts, feelings, and behaviors that are at odds with their self-image or social values (e.g., Jordan et al., 2015). Thirdperson data can complement self-reports: For instance, a study examining the effects of a mindfulness intervention on pro-environmental behavior (Frank et al., 2019) ideally also collects data on participants' actual behaviors instead of solely relying on their reports in this respect. Yet, another way to advance QMPR could be to take a closer look at dropouts and former mindfulness practitioners. These populations might have different-and perhaps less positiveexperiences with and perceptions of mindfulness practice and hence could provide a valuable source of information on these practices.

In sum, QMPR has considerable potential for advancing the understanding of mindfulness practice. To better tap this potential, we think that future qualitative research should more strongly (1) include second- and third-person data, (2) include dropouts or former mindfulness practitioners, (3) fully disclose details on the mindfulness practice under inquiry and the applied analytical procedure, including its underlying ideological, epistemological, and ontological assumptions, (4) apply critical and deconstructivist research paradigms and methods, such as discourse analysis or conversation analysis, especially to avoid the overemphasis on 
positive effects when studying mindfulness practice, (5) conduct pluralistic qualitative research, and (6) build adversarial research teams when inquiring into mindfulness practice. Publishers and reviewers can also contribute to advance QMPR by taking these criteria into consideration.

\section{Limitations and Future Research}

Our scoping review comes along with several limitations. We consider six limitations especially noteworthy. Whereas the first three concern our study more generally, the last three pertain to the search string applied in our review.

First, we have not followed reporting guidelines for scoping reviews, as suggested by Tricco et al. (2018). We were not aware of these guidelines when conducting this study. We think that following these guidelines from the very beginning would have helped to further increase the transparency of our review.

Second, the review was limited to the databases SCOPUS and Web of Science (WoS). Other relevant databases, such as Google Scholar or discipline-focused databases (e.g., PubMed, PsycInfo), were not consulted. The purpose of our study was to provide an overview of general trends in QMPR, and this trend is certainly reflected by SCOPUS and WoS. Nevertheless, a more detailed search using disciplinespecific databases might yield a more complete picture of QMPR, especially its application in specific disciplines.

Third, while we promote critical and deconstructionist approaches to evaluating mindfulness in this study, our review itself stays close to an aggregative summing up of trends and omissions. Such an aggregation comes along with its own shortcomings and omissions: for example, we summed up studies based on the analytical procedure outlined in the article. However, it is possible to integrate critical perspectives in a thematic or content analysis without referring to a different analytical method for this purpose. Since our study did not analyze the results in-depth, however, we were not able to provide such differentiated (and critical) perspectives on our study sample. Nevertheless, we think that such a summing up provides a first basis for future research aiming to further advance the reflection of QMPR, which can be grounded in different analytical paradigms.

Fourth, our search string incorporated MBSR and MBCT practices but did not explicitly include other MBIs (or the general term "MBI"). This partly explains why our results predominantly yielded studies focusing on MBSR, MBCT, or adapted versions of these MBIs. An explicit search for other MBIs would probably have altered the results. Nevertheless, our review did identify other MBIs, and their distribution is in line with general tendencies observed within mindfulness research during the last decade (Chiesa \& Malinowski, 2011; van Dam et al., 2018). Furthermore, it was already mentioned that our study aims to provide an overview of current trends in QMPR, without making any claim for completeness.

Fifth, the search string was formulated in such a way that it did not include specific types of mindfulness meditations, such as body scan or breath observation, unless they were not described as mindfulness practice (which is not evident). Given that mindfulness scholars have called for more specificity in mindfulness research (van Dam et al., 2018), it is possible that recent studies focused on such specific mindfulness meditations and therefore might not have been identified using our search string.

Sixth, our search string only included the term "qualitative" in order to identify QMPR. It did not, however, include specific qualitative methods. Therefore, it is possible that we have missed articles that did not describe themselves as "qualitative" and instead only mentioned the specific method (e.g., grounded theory, discourse analysis). Nevertheless, our inductive, iterative review approach has the advantage that it could identify articles in which the exact method was not specified or in which methods were applied we were not aware of (e.g., relational-centered research, integrative interview approach). Against this background, we think again that our research can provide a starting point for more specific follow-up analyses on QMPR.

Supplementary Information The online version contains supplementary material available at https://doi.org/10.1007/s12671-021-01748-9.

Author contribution PF: designed and supervised the study, participated in the data collection, coordinated and participated in the data analyses, and wrote the paper. MM: executed the data collection, participated in the data analysis, designed the figures, and participated in writing the paper.

Funding Open Access funding enabled and organized by Projekt DEAL.

\section{Declarations}

Conflict of Interest The authors declare no competing interests.

Open Access This article is licensed under a Creative Commons Attribution 4.0 International License, which permits use, sharing, adaptation, distribution and reproduction in any medium or format, as long as you give appropriate credit to the original author(s) and the source, provide a link to the Creative Commons licence, and indicate if changes were made. The images or other third party material in this article are included in the article's Creative Commons licence, unless indicated otherwise in a credit line to the material. If material is not included in the article's Creative Commons licence and your intended use is not permitted by statutory regulation or exceeds the permitted use, you will need to obtain permission directly from the copyright holder. To view a copy of this licence, visit http://creativecommons.org/licenses/by/4.0/. 


\section{References}

Arthington, P., (2016). Mindfulness: A critical perspective. Community Psychology in Global Perspective, 2(1), 87-104.

Baer, R. A., Smith, G. T., Hopkins, J., \& Toney, L., (2006). Using self-report assessment methods to explore facets of mindfulness. Assessment, 13(1), 27-45. https://doi.org/10.1177/1073191105 283504

Baer, R., (2019). Assessment of mindfulness by self-report. Current Opinion in Psychology, 28, 42-48. https://doi.org/10.1016/j. copsyc.2018.10.015

Baltzell, A. (2016). Mindfulness and performance. Cambridge University Press.

Baminiwatta, A., \& Solangaarachchi, I., (2021). Trends and developments in mindfulness research over 55 years: A bibliometric analysis of publications indexed in Web of Science. Mindfulness, 12(9), 2099-2116. https://doi.org/10.1007/S12671-021-01681-X

Hugh-Jones, S., Rose, S., Koutsopoulou, G. Z., \& Simms-Ellis, R., (2018). How is stress reduced by a workplace mindfulness intervention? A qualitative study conceptualising experiences of change. Mindfulness, 9(2), 474-487. https://doi.org/10.1007/ s12671-017-0790-2

Barrett, B., Grabow, M., Middlecamp, C., Mooney, M., Checovich, M. M., Converse, A. K., Gillespie, B., \& Yates, J., (2016). Mindful climate action: Health and environmental co-benefits from mindfulness-based behavioral training. Sustainability (switzerland), 8(10), 1-20. https://doi.org/10.3390/su8101040

Beauchemin, J., Hutchins, T. L., \& Patterson, F., (2008). Mindfulness meditation may lessen anxiety, promote social skills, and improve academic performance among adolescents with learning disabilities. Complementary Health Practice Review, 13(1), 34-45. https://doi.org/10.1177/1533210107311624

Bergomi, C., Tschacher, W., \& Kupper, Z., (2013). The assessment of mindfulness with self-report measures: Existing scales and open issues. Mindfulness, 4(3), 191-202.

Brooks, J., \& King, N. (2012). Qualitative psychology in the real world: the utility of template analysis. Paper presented at British psychological society annual conference.

Charmaz, K., (2000). Constructing grounded theory: A practical guide through qualitative analysis. Sage Publications.

Chiesa, A., Calati, R., \& Serretti, A., (2011). Does mindfulness training improve cognitive abilities? A systematic review of neuropsychological findings. Clinical Psychology Review, 31(3), 449-464. https://doi.org/10.1016/j.cpr.2010.11.003

Chiesa, A., \& Malinowski, P., (2011). Mindfulness-based approaches: Are they all the same? Journal of Clinical Psychology, 67(4), 404-424. https://doi.org/10.1002/jclp.20776

Clarke, A., (2005). Situational analysis: Grounded theory after the postmodern turn. Sage Publications.

Corbin, J., \& Strauss, A.L. (2008). Basics of qualitative research: Techniques and procedures for developing grounded theory (3rd ed.). Sage Publications.

Cormack, D., Jones, F. W., \& Maltby, M., (2018). A "Collective Effort to Make Yourself Feel Better": The group process in mindfulnessbased interventions. Qualitative Health Research, 28(1), 3-15. https://doi.org/10.1177/1049732317733448

Cote, T., Baltzell, A., \& Diehl, R., (2019). A qualitative exploration of division I tennis players completing the mindfulness meditation training for sport 2.0 program. Sport Psychologist, 33(3), 203-212. https://doi.org/10.1123/TSP.2017-0155

Davidson, R. J., \& Kaszniak, A. W., (2015). Conceptual and methodological issues in research on mindfulness and meditation. American Psychologist, 70(7), 581-592. https://doi.org/10.1037/a0039512

DeJaeghere, J., Morrow, V., Richardson, D., Schowengerdt, B., Hinton, R., \& Boudet, A. (2019). Guidance note on qualitative research in education: Considerations for best practice. Department for International Development, prepared for Building Evidence in Education

Dorjee, D., (2010). Kinds and dimensions of mindfulness: Why it is important to distinguish them. Mindfulness, 1(3), 152-160. https://doi.org/10.1007/s12671-010-0016-3

Dussault, É., Fernet, M., \& Godbout, N., (2020). A metasynthesis of qualitative studies on mindfulness, sexuality, and relationality. Mindfulness, 11, 2682-2694. https://doi.org/10.1007/ s12671-020-01463-x

Ellis, C., (2004). The ethnographic I: A methodological novel about autoethnography. AltaMira Press.

Finlay, L., \& Evans, K., (2009). Relational centred research: Exploring meanings and experience. John Wiley.

Frank, P., Stanszus, L., Fischer, D., Kehnel, K., \& Grossman, P., (2019). Cross-fertilizing qualitative perspectives on effects of a mindfulness-based intervention: An empirical comparison of four methodical approaches. Mindfulness, 10(11), 2452-2467. https:// doi.org/10.1007/s12671-019-01227-2

Frost, N., (Ed.) (2011). Qualitative methods in psychology: combining core approaches. Open University Press.

Furedi, F., (2014). Mindfulness is a fad, not a revolution I Tes News. Retrieved April 8, 2020, from Tes News website: https://www.tes. com/news/mindfulness-fad-not-revolution

Garland, E., \& Gaylord, S., (2009). Envisioning a future contemplative science of mindfulness: Fruitful methods and new content for the next wave of research. Complementary Health Practice Review, 14(1), 3-9. https://doi.org/10.1177/1533210109333718

Giorgi, A., (2009). The descriptive phenomenological method in psychology. Duquesne University Press.

Glaser, B., (1992). Basics of grounded theory analysis. Sociology Press.

Goldberg, S. B., Tucker, R. P., Greene, P. A., Simpson, T. L., Hoyt, W. T., Kearney, D. J., \& Davidson, R. J., (2019). What can we learn from randomized clinical trials about the construct validity of selfreport measures of mindfulness? A meta-analysis. Mindfulness, 10, 775-785. https://doi.org/10.1007/s12671-018-1032-y

Goyal, M., Singh, S., Sibinga, E. M. S., Gould, N. F., Rowland-Seymour, A., Sharma, R., Berger, Z., Sleicher, D., Maron, D. D., Shihab, H. M., Ranasinghe, P. D., Linn, S., Saha, S., Bass, E. B., \& Haythornthwaite, J. A., (2014). Meditation programs for psychological stress and well-being: A systematic review and metaanalysis. JAMA Internal Medicine, 174(3), 357-368. https://doi. org/10.1001/jamainternmed.2013.13018

Grossman, P., (2008). On measuring mindfulness in psychosomatic and psychological research. Journal of Psychosomatic Reseatch, 64, 405-408. https://doi.org/10.1308/003588408x261681

Grossman, P., (2019). On the porosity of subject and object in 'mindfulness' scientific study: Challenges to 'scientific' construction, operationalization and measurement of mindfulness. Current Opinion in Psychology, 28, 102-107. https://doi.org/10.1016/j. copsyc.2018.11.008

Hanley, A. W., Abell, N., Osborn, D. S., Roehrig, A. D., \& Canto, A. I., (2016). Mind the gaps: Are conclusions about mindfulness entirely conclusive? Journal of Counseling and Development, 94(1), 103-113. https://doi.org/10.1002/jcad.12066

Helfferich C \& Kruse J., (2007). Hermeneutisches Fremdverstehen als eine sensibilisierende Praxeologie für sozialarbeiterische Beratungskontexte. Oder: Vom "professionellen Blick" zum "hermeneutischen Ohr". Leverkusen: Barbara-Budrich.

Hewitt-Taylor, J., (2001). Use of constant comparative analysis in qualitative research. Nursing Standard, 15(42), 39-42. https://doi.org/ 10.7748/ns2001.07.15.42.39.c3052

Hyland, T., (2017). McDonaldizing spirituality. Journal of Transformative Education, 15(4), 334-356. https://doi.org/10.1177/15413 44617696972 
Ivtzan, I., (Ed.). (2019). Handbook of mindfulness-based programmes. Mindfulness interventions from education to health and therapy. Routledge.

Jha, A. P., Morrison, A. B., Dainer-Best, J., Parker, S., Rostrup, N., \& Stanley, E. A., (2015). Minds "at attention": Mindfulness training curbs attentional lapses in military cohorts. PLOS ONE, 10(2), 1-19. https://doi.org/10.1371/journal.pone.0116889

Jiga, K., Kaunhoven, R. J., \& Dorjee, D., (2019). Feasibility and efficacy of an adapted mindfulness-based intervention (MBI) in areas of socioeconomic deprivation (SED). Mindfulness, 10(2), 325-338. https://doi.org/10.1007/s12671-018-0977-1

Jordan, J., Leliveld, M. C., \& Tenbrunsel, A. E., (2015). The moral self-image scale: Measuring and understanding the malleability of the moral self. Frontiers in Psychology, 6, 1878. https://doi.org/ 10.3389/fpsyg.2015.01878

Keller, R., (2011). The sociology of knowledge approach to discourse (SKAD). Human Studies, 34(1), 43-65.

Kerr, C. E., Josyula, K., \& Littenberg, R., (2011). Developing an observing attitude: An analysis of meditation diaries in an MBSR clinical trial. Clinical Psychology and Psychotherapy, 18(1), 80-93. https://doi.org/10.1002/cpp.700

Krägeloh, C., Henning, M. A., Medvedev, O. N., Feng, X. J., Moir, F., Billington, R., \& Siegert, R. J. (2019). Meta-theories and qualitative methods in mindfulness research. In: C. Krägeloh, M. A. Henning, O. N. Medvedev, X. J. Feng, F. Moir, R. Billington, \& R. J. Siegert (Eds.), Mindfulness-based intervention research (pp. 31-56). Routledge.

Larkin, H., Hardiman, E. R., Weldon, T., \& Kim, H. C., (2012). Program characteristics as factors influencing the implementation of mindfulness meditation in substance abuse treatment agencies. Journal of Religion and Spirituality in Social Work, 31(4), 311327. https://doi.org/10.1080/15426432.2012.716284

Lau, M. A., Bishop, S. R., Segal, Z. V., Buis, T., Anderson, N. D., Carlson, L., Shapiro, S., Carmody, J., Abbey, S., \& Devins, G., (2006). The Toronto mindfulness scale: Development and validation. Journal of Clinical Psychology, 62(12), 1445-1467. https:// doi.org/10.1002/jclp.20326

Lindahl, J. R., Fisher, N. E., Cooper, D. J., Rosen, R. K., \& Britton, W. B., (2017). The varieties of contemplative experience: A mixedmethods study of meditation-related challenges in Western Buddhists. PLoS ONE, 12(5), e0176239. https://doi.org/10.1371/journ al.pone. 0176239

Luberto, C. M., Shinday, N., Song, R., Philpotts, L. L., Park, E. R., Fricchione, G. L., \& Yeh, G. Y., (2018). A systematic review and meta-analysis of the effects of meditation on empathy, compassion, and prosocial behaviors. Mindfulness, 9(3), 708-724. https:// doi.org/10.1007/s12671-017-0841-8

Malpass, A., Carel, H., Ridd, M., Shaw, A., Kessler, D., Sharp, D., Bowden, M., \& Wallond, J., (2012). Transforming the perceptual situation: A meta-ethnography of qualitative work reporting patients' experiences of mindfulness-based approaches. Mindfulness, 3(1), 60-75. https://doi.org/10.1007/s12671-011-0081-2

Malpass, A., Binnie, K., \& Robson, L. (2019). Medical students' experience of mindfulness training in the UK: wellbeing, coping reserve and professional development. Education Research International, 10: 1155/2019/4021729. https://doi.org/10.1155/ 2019/4021729

Martinez, M. E., Kearney, D. J., Simpson, T., Felleman, B. I., Bernardi, N., \& Sayre, G., (2015). Challenges to enrollment and participation in mindfulness-based stress reduction among veterans: A qualitative study. Journal of Alternative and Complementary Medicine, 21(7), 409-421. https://doi.org/10.1089/acm.2014.0324

Mruck, K., \& Breuer, F., (2003). Subjectivity and reflexivity in qualitative research the FQS issues Forum Qualitative. Social Research, 4(2), 189-212. https://doi.org/10.17169/fqs-4.2.696

Munn, Z., Peters, M. D. J., Stern, C., Tufanaru, C., McArthur, A., \& Aromataris, E., (2018). Systematic review or scoping review?
Guidance for authors when choosing between a systematic or scoping review approach. BMC Medical Research Methodology, 18(1). https://doi.org/10.1186/s12874-018-0611-x

Nowogrodzki, A., (2016). Power of positive thinking skews mindfulness studies. Nature. https://doi.org/10.1038/nature.2016.19776

Paul, J., \& Criado, A. R., (2020). The art of writing literature review: What do we know and what do we need to know? International Business Review, 29(4), 101717. https://doi.org/10.1016/j.ibusr ev.2020.101717

Quaglia, J. T., Brown, K. W., Lindsay, E. K., Creswell, J. D., \& Goodman, R. J., (2016). From conceptualization to operationalization of mindfulness. In Handbook of Mindfulness, Theory, Research, and Practice (pp. 151-170).

Reb, J., \& Atkins, P. W. B., (2015). Mindfulness in organizations: foundations, research, and applications. In Cambridge Companions to Management. Mindfulness in Organizations: Foundations, Research, and Applications (pp. 409-418). Cambridge: Cambridge University Press.

Reichertz, J., (2013). Gemeinsam interpretieren : die Gruppeninterpretation als kommunikativer Prozess. Springer VS.

Reveley, J., (2016). Neoliberal meditations: How mindfulness training medicalizes education and responsibilizes young people. Policy Futures in Education, 14(4), 497-511. https://doi.org/10.1177/ 1478210316637972

Ritchie, J., \& Spencer, L. (1994). Qualitative data analysis or applied policy research. In: A. Bryman, R. G. Burgess (Eds.), Analysing qualitative data (pp. 173-194). Routledge

Schonert-Reichl, K., \& Roeser, R., (Eds.). (2016). Handbook of mindfulness in education: Integrating theory and research into practice. Springer.

Smith, J. A., \& Osborn, M., (2008). Interpretative phenomenological analysis. In J. Smith (Ed.), Qualitative psychology: A practical guide to research methods (pp. 53-80). Sage.

Stanszus, L., D. Fischer, T. Böhme, P. Frank, J. Fritzsche, J. Harfensteller, S. Geiger, P. Grossman, \& Schrader, U. (2017). Education for sustainable consumption through mindfulness training-development of a consumption-specific intervention. Journal for Teacher Education in Sustainability, 19(1), 5-21.

Stanszus, L. S., Frank, P., \& Geiger, S. M. (2019). Healthy eating and sustainable nutrition through mindfulness? Mixed method results of a controlled intervention study. Appetite, 141, 104325. https:// doi.org/10.1016/j.appet.2019.104325

Tricco, A. C., Lillie, E., Zarin, W., O'Brien, K. K., Colquhoun, H., Levac, D., Moher, D., Peters, M. D. J., Horsley, T., Weeks, L., Hempel, S., Akl, E. A., Chang, C., McGowan, J., Stewart, L., Hartling, L., Aldcroft, A., Wilson, M. G., Garritty, C., \& Straus, S. E., (2018). PRISMA extension for scoping reviews (PRISMA$\mathrm{ScR})$ : Checklist and explanation. Annals of Internal Medicine., 169(7), 7-473. https://doi.org/10.7326/M18-0850

Van Dam, N. T., van Vugt, M. K., Vago, D. R., Schmalzl, L., Saron, C. D., Olendzki, A., Meissnert, T., Lazar, S. W., Kerr, C. E., Gorchov, J., Fox, K. C. R., Field, B. A., Britton, W. B., BrefczynskiLewis, J. A., \& Meyer, D. E., (2018). Mind the hype: A critical evaluation and prescriptive agenda for research on mindfulness and meditation. Perspectives on Psychological Science, 13(1), 36-61. https://doi.org/10.1177/1745691617709589

Walsh, Z., (2016). A meta-critique of mindfulness critiques: From McMindfulness to critical mindfulness. In: R. E. Purser, D. Forbes, \& T. A. Burke (Eds.), Handbook of mindfulness: Culture context, and social engagement. (pp. 153-166). Springer.

Wooffitt, R., \& Holt, N. (2011). Looking in and speaking out. Introspection, consciousness, communication. Exeter: Imprint Academic.

Yin, R. K. (2013). Case study research: Design and methods. Sage.

Publisher's Note Springer Nature remains neutral with regard to jurisdictional claims in published maps and institutional affiliations. 